\title{
A review of present techniques and methodological advances in analyzing ${ }^{234} \mathrm{Th}$ in aquatic systems
}

Michiel Rutgers van der Loeff ${ }^{1}$, Manmohan M. Sarin ${ }^{2}$, Mark Baskaran ${ }^{3}$, Claudia Benitez-Nelson ${ }^{4}$, Ken O. Buesseler ${ }^{5}$, Matt Charette ${ }^{5}$, Minhan Dai ${ }^{6}$, Örjan Gustafsson ${ }^{7}$, Pere Masque ${ }^{8}$, Paul J. Morris ${ }^{9}$, Kent Orlandini ${ }^{10}$, Alessia Rodriguez y Baena ${ }^{11}$, Nicolas Savoye ${ }^{12}$, Sabine Schmidt ${ }^{13}$, Robert Turnewitsch $^{9}$, Ingrid Vöge ${ }^{1}$, James T. Waples ${ }^{14}$.

${ }^{1}$ Alfred-Wegener Institute for Polar and Marine Research, D 27570 Bremerhaven, Germany

${ }^{2}$ Physical Research Laboratory, Ahmedabad, India

${ }^{3}$ Dept. of Geology, Wayne State University, Detroit, MI-48202, USA

${ }^{4}$ Dept. of Geological Sciences/Marine Science Program, University of South Carolina, Columbia, SC 29208 USA

${ }^{5}$ Dept. of Marine Chemistry and Geochemistry, Woods Hole Oceanographic Institution, Woods Hole, MA 02543 USA

${ }^{6}$ State key laboratory of Marine Environmental Science, Xiamen University, Xiamen 361005, China

${ }^{7}$ Stockholm University, Institute of Applied Environmental Research, 10691 Stockholm, Sweden

${ }^{8}$ Institut de Ciència i Tecnologia Ambientals, Universitat Autònoma de Barcelona, 08193 Bellaterra, Spain

${ }^{9}$ National Oceanography Centre, Southampton (NOCS), UK

${ }^{10}$ Environmental Research Division, Argonne National Laboratory, Argonne, IL 60439, USA

${ }^{11}$ IAEA Marine Environment Laboratory, Monaco and Dip.Te.Ris., University of Genova, Italy

${ }^{12}$ Dept. of Analytical and Environmental Chemistry, Vrije Universiteit Brussel, B1050 Brussels, Belgium

${ }^{13}$ Département de Géologie et Océanographie, Université Bordeaux 1, 33405 Talence Cedex, France

${ }^{14}$ Great Lakes WATER Institute, University of Wisconsin-Milwaukee, Milwaukee, WI 53204, USA

corresponding author:

Rutgers van der Loeff, Michiel

emailmloeff@awi-bremerhaven.de

Tel: +49 47148311259 Fax: +49 47148311425

accepted for publication in Marine Chemistry "FATE" volume 


\section{Abstract}

The short-lived thorium isotope ${ }^{234}$ Th (half-life 24.1 days) has been used as a tracer for a variety of transport processes in aquatic systems. Its use as a tracer of oceanic export via sinking particles has stimulated a rapidly increasing number of studies that require analyses of ${ }^{234} \mathrm{Th}$ in both marine and freshwater systems. The original ${ }^{234} \mathrm{Th}$ method is labour intensive. Thus, there has been a quest for simpler techniques that require smaller sample volumes. Here, we review current methodologies in the collection and analysis of ${ }^{234} \mathrm{Th}$ from the water column, discuss their individual strengths and weaknesses, and provide an outlook on possible further improvements and future challenges. Also included in this review are recommendations on calibration procedures and the production of standard reference materials as well as a flow chart designed to help researchers find the most appropriate ${ }^{234} \mathrm{Th}$ analytical technique for a specific aquatic regime and known sampling constraints.

Keywords : ${ }^{234} \mathrm{Th}$, methodology, sampling, analytical techniques, export

\section{Introduction}

Thorium is one of the most widely used tracers of particle cycling in the world's oceans. Its extensive usefulness is due to both the well characterized production rates of thorium isotopes (viz. ${ }^{234} \mathrm{Th}$ and ${ }^{230} \mathrm{Th}$ ) from their soluble uranium parents $\left({ }^{238} \mathrm{U}\right.$ and $\left.{ }^{234} \mathrm{U}\right)$ and their high particle reactivity in seawater. The constant production and scavenging rates of ${ }^{230} \mathrm{Th}\left(\mathrm{t}_{1 / 2}\right.$ $=75,400 \mathrm{y}$ ) in the deep sea are well recognized for studying processes on time scales of thousands of years, whereas short-lived ${ }^{234} \mathrm{Th}\left(\mathrm{t}_{1 / 2}=24.1 \mathrm{~d}\right)$ is most suitable for processes occurring in the surface ocean on time scales of days to months. Although ${ }^{234} \mathrm{Th}$ has been extensively used in a wide range of applications (Cochran and Masqué 2003; Waples et al. 2005), its potential usefulness in quantifying particle export from the upper ocean (Coale and Bruland 1985; Eppley 1989) has been the impetus for a large number of recent studies. This specific interest has led to the continuous development of analytical techniques with regard to ${ }^{234}$ Th sampling, its pre-concentration from seawater and detection capabilities. These analytical improvements include reduction of sample size and refinement of radiochemical separation steps, which allows a corresponding increase in sample throughput and spatial resolution. Some of the earlier methods have become obsolete, but many others deserve merit for specific applications. As such there is no single best technique for the collection and 
measurement of ${ }^{234} \mathrm{Th}$ in aquatic ecosystems. In this paper, we provide an overview of the existing methods with a summary of their advantages and disadvantages. Our objective is to provide a suitable guide for selecting the most appropriate technique for a specific application and location. We also identify some unresolved analytical issues and provide a list of recommendations for further improvement and inter-calibration of ${ }^{234} \mathrm{Th}$.

Details of ${ }^{234} \mathrm{Th}$ speciation, modelling, conversion of ${ }^{234} \mathrm{Th}$ flux into the flux of carbon and other elements, and fields of expected future applications of ${ }^{234} \mathrm{Th}$ can be found in companion papers of Santschi et al. (2005), Savoye et al. (2005), Buesseler et al. (2005), and Waples et al. (2005), respectively, in this issue.

\section{Sampling and radiochemical purification methods}

\subsection{Co-precipitation with $\mathrm{Fe}(\mathrm{OH})_{3}$ :}

One of the first methods used for the extraction of ${ }^{234} \mathrm{Th}$ from seawater involves coprecipitation with ferric hydroxide $\left(\mathrm{Fe}(\mathrm{OH})_{3}\right)$ from 20 - $30 \mathrm{~L}$ of seawater (Bhat et al. 1969). The ${ }^{234} \mathrm{Th}$ was subsequently separated and purified on an anion-exchange column, electrodeposited on a stainless steel disc, and counted on a low-level beta counter. This procedure is somewhat labor intensive as ${ }^{238} \mathrm{U}$ is also co-precipitated with the $\mathrm{Fe}(\mathrm{OH})_{3}$, with variable efficiency (Buesseler et al., 2001). Thus, it is essential to know the amount of $U$ incorporated in the precipitate in order to determine the in-growth of ${ }^{234} \mathrm{Th}$ from $\mathrm{U}$ decay. In marine systems, the amount of $U$ that co-precipitates with $\mathrm{Fe}(\mathrm{OH})_{3}$ appears to depend on the amount of Fe added (Smith et al. 2004) and on the stability of the uranium-carbonate complex. A quantitative co-precipitation of ${ }^{238} \mathrm{U}$ is achievable by purging the seawater sample with $\mathrm{N}_{2}$-gas before neutralization of the acidified sample (Sarin 1992; Sarin et al. 1994; Sarin et al. 1996; Rengarajan et al. 2003). On the other hand, it is suggested that neutralization with a carbonate containing ammonia solution may be used to prevent any $U$ from precipitating. In fresh water systems, Waples et al. (2003) determined U co-precipitation scavenging efficiency of $17 \pm 2.6 \%$ in Lake Michigan where $\Sigma \mathrm{CO}_{2} \approx 2.2 \mathrm{mM}$ (see section 5.3).

However, it is suggested that for a specific region of study, the ${ }^{238} \mathrm{U}$ concentration in the precipitate be precisely measured in order to make appropriate in-growth corrections for ${ }^{234} \mathrm{Th}$. This requires addition of a $\mathrm{U}$ spike (e.g. ${ }^{232} \mathrm{U}$ or $\left.{ }^{236} \mathrm{U}\right)$. The in-growth corrections can be minimized by radiochemical purification of Th from $U$ as soon as possible after the collection and pre-concentration step, followed by beta or gamma counting of the purified source. The in-growth correction for ${ }^{234} \mathrm{Th}$ (from ${ }^{238} \mathrm{U}$ ) is $\leq 5 \%$ if the time interval between sample collection and Th-U separation is $<2$ days (see Section 2.3). 


\subsection{Adsorption on $\mathrm{MnO}_{2}$ impregnated cartridges}

Over the past decade, $\mathrm{MnO}_{2}$-impregnated filter cartridges have been used for the preconcentration of ${ }^{234} \mathrm{Th}$ from a wide range of seawater environments. The main advantage of $\mathrm{MnO}_{2}$ over $\mathrm{Fe}(\mathrm{OH})_{3}$ is that $\mathrm{MnO}_{2}$ does not scavenge $\mathrm{U}$ when it is produced without prior acidification, i.e. when $\mathrm{U}$ is complexed with carbonate. Therefore $\mathrm{MnO}_{2}$ effectively separates Th from its U parent. Mann et al. (1984) were the first to use $\mathrm{MnO}_{2}$ impregnated filter cartridges connected in series for the extraction of transuranics from seawater. A filter cartridge was used to retain the particulate matter immediately before the two Mn-cartridges. Since then, many researchers have used in-situ pumps with particle filters and $\mathrm{MnO}_{2}$ cartridges for the pre-concentration of radionuclides from oceanic waters (e.g. Nozaki et al. 1981; Bacon and Anderson 1982; Buesseler et al. 1992; Baskaran et al. 1993; Cochran et al. 1995; Guo et al. 1995; Baskaran et al. 1996; Moran et al. 1997; Guo et al. 2002; Baskaran et al. 2003). The Mn-fiber cartridges (or the fiber alone after removing it from the plastic core) are usually ashed in a muffle furnace and ${ }^{234} \mathrm{Th}$ is quantified on a gamma spectrometer. As an alternative to the ashing process, the cartridges may be melted or crushed (Hartman and Buesseler 1994) into a standardized geometry (Buesseler et al. 1992). Entire cartridges may also be leached in an acid $(>3 \mathrm{~N} \mathrm{HCl}$ ) re-circulating system (Rutgers van der Loeff and Berger 1993). An elegant procedure has been developed by Hanfland et al. (pers. comm.) in which the entire cartridge is leached in a Soxhlet system with $6 \mathrm{~N} \mathrm{HCl}$; an adaptation of the leaching technique developed by Moore (Rutgers van der Loeff and Moore, 1999). This leaching takes several days and has a recovery of approximately $95 \%$.

The filter cartridge technique is often used with large volume samples. It has the advantage that the same sample can be used for the analysis of several radionuclides, such as ${ }^{234} \mathrm{Th},{ }^{230} \mathrm{Th},{ }^{231} \mathrm{~Pa},{ }^{210} \mathrm{~Pb}$ and Ra isotopes (Baskaran et al. 1993; Colley and Thomson 1994; Baskaran and Santschi 2002). The large volumes processed $\left(10^{2}-10^{4} \mathrm{~L}\right)$ also allow for the determination of ${ }^{234} \mathrm{Th}$ and other elements in various particle size classes (e.g. Guo et al. 2002), essential for many studies. A major disadvantage is the large amount of ship time required for the in situ filtration, the significant expense of large volume pumping systems and the need to measure at least a filter and two cartridges, i.e. 3 samples, for every single estimate of total ${ }^{234} \mathrm{Th}$ activity. This also limits the spatial coverage of the ${ }^{234} \mathrm{Th}$ profiles.

The activity of ${ }^{234} \mathrm{Th}$ absorbed on the first $\mathrm{MnO}_{2}$-coated filter cartridge is calculated by using the following equation: 
where $\mathrm{E}$ is the collection efficiency, $\mathrm{A}$ and $\mathrm{B}$ are the activities of the first and second cartridge, respectively (Livingston and Cochran 1987). The fundamental assumption of the $\mathrm{Mn}$-cartridge extraction method with two $\mathrm{MnO}_{2}$-coated cartridges connected in series, is "uniform extraction of Th", i.e. both cartridges retain a constant percentage of the Thentering into that cartridge. However, field data show large sample to sample variations in the extraction efficiency, ranging from $<65 \%$ to $\sim 100 \%$. Livingston and Cochran (1987) found Th-extraction efficiency of $\mathrm{MnO}_{2}$-coated polypropylene cartridges to vary between 69 and 93 $\%$ (mean: $82.7 \%, \mathrm{n}=12$ ). Subsequent workers have reported a comparable variability (e.g. Cochran et al. 1987; e.g. Bacon et al. 1989; Buesseler et al. 1992; Baskaran et al. 1993; Buesseler et al. 1995; Cochran et al. 1995; Guo et al. 1995; Baskaran et al. 1996; Moran et al. 1997; Charette and Moran 1999; Benitez-Nelson et al. 2000; Guo et al. 2002; Baskaran et al. 2003; Trimble and Baskaran 2005).

These variations are presumably caused by one or several of the following: a) individual variations in the absolute efficiencies of one or both cartridges due to changes in the contact time of seawater with $\mathrm{MnO}_{2}$-surface (e.g. flow rates); b) limited adsorption sites on the cartridges, c) ${ }^{234}$ Th speciation or complexation by colloids, d) loss of $\mathrm{MnO}_{2}$ particles from the first Mn-cartridge to the second, e) partial or total retention on the second Mncartridge of Th released from the first Mn-cartridge during filtration, f) variations in the amount of particulate Th retained by the prefilter (which would result in a major portion ending up on the first $\mathrm{MnO}_{2}$-filter cartridge) and g) bypass of water around cartridge, i.e. poor sealing of the cartridge in the housing. Some of these issues are discussed here in more detail.

The relationship between flow rate and Mn cartridge collection efficiency remains ambiguous. Although Buesseler et al. (1992) and Baskaran et al. (1993) did not find a correlation between relative efficiency and flow rates, Cochran et al. (1995) and Charette and Moran (1999) observed a weak inverse relationship (Figure 1), suggesting that adsorption of ${ }^{234} \mathrm{Th}$ on the $\mathrm{MnO}_{2}$ fiber is kinetically limited (Cochran et al. 1995; Charette and Moran 1999; Guo et al. 2002). Charette and Moran (1999) observed no dependence of the extraction efficiency on the volume of seawater that is processed (up to $\sim 2000 \mathrm{~L} ; 8.5 \mathrm{~cm}$ cartridge), suggesting that adsorption sites for ${ }^{234} \mathrm{Th}$ are non-limiting even at such high volumes.

Variable extraction efficiency of $\mathrm{MnO}_{2}$ cartridges may also be related to electrostatic repulsion between the $\mathrm{MnO}_{2}$ surface and the filter-passing submicron ${ }^{234} \mathrm{Th}$ complex. Amorphous $\mathrm{MnO}_{2}$ formed by reduction of $\mathrm{KMnO}_{4}$ has a reported isoelectric point (or $\mathrm{pH}$ 
point of zero charge) in the range 1.5-3, depending on formation conditions (e.g. Appelo and Postma 1999; Tonkin et al. 2004). Consequently, the $\mathrm{MnO}_{2}$ adsorbers carry a net negative charge at seawater $\mathrm{pH}$. In seawater, Th appears to be complexed by organic compounds, such as humic acids and acidic polysaccharides, and incorporated into submicron colloids, which also carry a net negative charge (see Santschi et al. 2005). Hence, repulsion between these Th complexes and the $\mathrm{MnO}_{2}$ surface may occur, thereby reducing collection efficiency. Thus, the traditional approach of calculating and correcting for the $\mathrm{MnO}_{2}$ collection efficiency using the assumption of identical speciation would need to be reevaluated.

Indirect evidence seems to support the hypothesis that some fraction of the Th in solution is being less efficiently collected by $\mathrm{MnO}_{2}$ cartridges. For example, $\mathrm{MnO}_{2}$ cartridges were employed on several cruises in the Gulf of Maine (e.g. Gustafsson et al. 1997; Gustafsson et al. 1998; Benitez-Nelson et al. 2000) and in Bothnian Bay in the northernmost Baltic Sea (Gustafsson et al. 2000). In these coastal settings the ${ }^{234} \mathrm{Th}$ collection efficiencies decreased with increasing total organic carbon (TOC) loads (Figure 2.a). This is consistent with a decrease in collection efficiency due to increased Th complexation by negatively charged organic ligands. To further test whether a portion of ${ }^{234} \mathrm{Th}$ in coastal waters is "missed" due to repulsion between ligand complex and $\mathrm{MnO}_{2}$ surface, the standard sampling protocol of a cartridge filter followed by two serial $\mathrm{MnO}_{2}$ adsorbers (referred to here as $\mathrm{Mn}-\mathrm{A}$ and $\mathrm{Mn}-\mathrm{B}$ ), was complemented with parallel samples collected with a cartridge filter followed by $1-\mathrm{kD}$ cross-flow ultrafiltration (CFF; Millipore Pellicon2). The CFF retentate was precipitated and the permeate was subsequently passed through mini "Mn foam" adsorbers at low flow rates (Gustafsson, unpublished results). The total ${ }^{234} \mathrm{Th}$ activity collected with the addition of the CFF was in good agreement with that collected with the standard Mn-cartridge procedure in offshore and subsurface locations (e.g., Wilkinson Basin in the open Gulf of Maine; Figure 2b). However, this agreement faltered in coastal and increasingly TOC rich waters, consistent with the hypothesis that colloidal ${ }^{234} \mathrm{Th}$ containing species are not quantitatively collected with regular $\mathrm{MnO}_{2}$-impregnated adsorbers. In a recent study, Cai et al. (2005a) used both the $\mathrm{MnO}_{2}$ cartridge and 4L methods to measure ${ }^{234} \mathrm{Th}$ in the South China Sea. These researchers found consistently lower apparent ${ }^{234} \mathrm{Th}$ activities using the $\mathrm{MnO}_{2}$ cartridges and they saw a lower collection efficiency on the second (B) vs. the first (A) cartridge. They attribute the behaviour to at least 3 forms of ${ }^{234} \mathrm{Th}$ - one that is easily adsorbed (removed most efficiently on cartridge $\mathrm{A}$ ), one that is complexed and thus has a lower collection efficiency, and a fraction that is caught on neither the A or B cartridge (but is traced in the small volume sample by equilibration with the yield monitor). The consequences 
of these low and variable collection efficiencies would be a systematically low ${ }^{234} \mathrm{Th}$ activity at all depths.

\subsection{Co-precipitation with $\mathrm{MnO}_{2}$}

In comparison to large volume sampling with $\mathrm{MnO}_{2}$-cartridges/absorbers, Rutgers van der Loeff adopted a $\mathrm{MnO}_{2}$ co-precipitation technique for ${ }^{234} \mathrm{Th}$ from $20 \mathrm{~L}$ of seawater. Because of its high selectivity for Th, in-growth from $\mathrm{U}$ via $\mathrm{MnO}_{2}$ co-precipitation is negligible (less than $0.5 \%$ of the uranium content of the sample is co-precipitated with $\mathrm{MnO}_{2}$, Benitez-Nelson et al. 2001). More recently, modified $\mathrm{MnO}_{2}$ co-precipitation procedures using small sample sizes ( 2 to 5 L) have been developed by Buesseler et al. (2001) and tested by Benitez-Nelson et al. (2001) in order to obtain higher temporal and spatial resolution. The earlier method for large volume samples ( 20 L) was largely based on the success of achieving greater reproducibility $( \pm 3.2 \%)$ and higher recovery $(>97 \%)$ of ${ }^{234} \mathrm{Th}$ (Buesseler et al., 2001). Thus, no internal tracer is required. For small volume samples, however, this reproducibility is more difficult to maintain, particularly when large numbers of samples are processed. As a result, Pike et al. (2005) reintroduced the use of yield tracers, as originally proposed by Bhat et al. (1969) when they used the $\mathrm{Fe}(\mathrm{OH})_{3}$ co-precipitation technique followed by ion-exchange separation of Th and U. In essence, Pike et al. (2005) used ${ }^{230} \mathrm{Th}$ to trace co-precipitation of ${ }^{234} \mathrm{Th}$ by $\mathrm{MnO}_{2}$ and a second spike $\left({ }^{229} \mathrm{Th}\right)$ to correct for losses of ${ }^{230}$ Th during ion-exchange chemistry. Both ${ }^{230} \mathrm{Th}$ and ${ }^{229} \mathrm{Th}$ are measured using ICP-MS. They found average recoveries of $91 \%$, but with occasional low recoveries of only $25 \%$.

Given the limited accessibility of high-resolution ICP-MS instruments, an alternative method for measuring ${ }^{230} \mathrm{Th}$ is to use alpha spectrometry. Cai et al. (2005b) recently developed a procedure to transfer the Th from a $\mathrm{MnO}_{2}$ to $\mathrm{Fe}(\mathrm{OH})_{3}$ phase in the presence of a ${ }^{228} \mathrm{Th}$ spike. The final $\mathrm{Fe}(\mathrm{OH})_{3}$ precipitate is processed using routine ion-exchange chemistry described by Anderson and Fleer (1982). Finally, Th is electroplated and counted by alpha spectrometry until the uncertainty on the ${ }^{230} \mathrm{Th} /{ }^{228} \mathrm{Th}$ ratio is lower than $3 \%$. A similar approach coupling UTEVA ${ }^{\circledR}$ extraction chromatography, $\mathrm{Nd}^{3+}$ co-precipitation and alphaspectrometry has been developed by Rodriguez y Baena et al. (2005).

In order to further test the reliability of small volume techniques in ${ }^{234} \mathrm{Th}$ collection, a comparison was made between $4 \mathrm{~L}$ samples with yield tracer (Pike et al. 2005) and $20 \mathrm{~L}$ samples (Bertoïa 2005), without yield tracer (Rutgers van der Loeff and Moore 1999). This experiment was conducted in the Southern Ocean during the European Iron Fertilization Experiment (EIFEX). Two seawater aliquots (4 L and $20 \mathrm{~L})$ were sampled at different depths 
over a period of $\sim 1$ month. Pairs of 4 and $20 \mathrm{~L}$ samples were collected from the same depth during a single sampling cast, with the exception of the surface samples. Four-Liter surface samples were collected from water bottles whereas a $20 \mathrm{~L}$ aliquot was sampled simultaneously from the ship's seawater supply. Overall, 21 pairs of samples were collected from different depths ranging from the surface down to $350 \mathrm{~m}$. Differences in ${ }^{234} \mathrm{Th}$ activity between the 4 and $20 \mathrm{~L}$ samples $\left({ }^{234} \mathrm{Th}_{4 \mathrm{~L}-20 \mathrm{~L}}\right)$ were usually less than $\pm 5 \%$ and appeared to be mainly due to counting uncertainties (Figure 3). Thus, there is no clear evidence of bias introduced in total ${ }^{234} \mathrm{Th}$ measurements by reducing sample size or by deleting the tracer in the 20 -L method.

The $20-\mathrm{L}$ and small volume techniques have different advantages. The $20-\mathrm{L}$ technique allows analyzing the particulate and dissolved activities of ${ }^{234} \mathrm{Th}$ in a single aliquot, thus enabling the calculation of total ${ }^{234} \mathrm{Th}$ activity (particulate + dissolved) as well as its residence time in the two phases. Furthermore, the beta-counting time for satisfactory dissolved ${ }^{234} \mathrm{Th}$ assessment is lower for the $20 \mathrm{~L}$ technique (usually $\leq 6 \mathrm{~h}$ to reach a counting uncertainty $\leq 3$ $\%$ in open ocean environment). The main advantage of the $<5 \mathrm{~L}$ techniques is the convenience of handling small volumes. Multiple sampling casts are required for a $20 \mathrm{~L}$ sample whereas $<5 \mathrm{~L}$ technique usually allows simultaneous sampling of ${ }^{234} \mathrm{Th}$ with other parameters (e.g. nutrients, phytoplankton biomass, etc.). This simultaneous sampling enables direct comparison between ${ }^{234} \mathrm{Th}$ and other measurements in the same sample and minimizes issues associated with fine scale changes in water mass properties between bottles or subsequent water casts. Furthermore, this technique is advantageous for achieving better vertical, horizontal and temporal resolution whenever ship-time is a limiting factor.

The $\mathrm{MnO}_{2}$ co-precipitation procedure uses an adequate amount of reagents so that quantitative scavenging of ${ }^{234} \mathrm{Th}$ from $20 \mathrm{~L}$ of seawater is achievable ( $>99 \%$, Rutgers van der Loeff and Moore 1999). When $142 \mathrm{~mm}$ diameter filters are used, filtration time remains within acceptable limits (45 minutes for $1 \mu$ filters in open ocean settings), but these filters have to be folded to fit the $25 \mathrm{~mm}$ diameter counting window of low-background beta counters. The $\mathrm{MnO}_{2}$ precipitation time was set by convenience rather than by reaction kinetics.

The development of small volume techniques coincides with the transition to filtration onto $25 \mathrm{~mm}$ diameter filters ( 1 to $1.2 \mu$ pore size), to avoid errors associated with the filter folding procedure. Since filtration area decreased by a factor 32 while the volume decreased only by a factor 4 , filtration has become a time-limiting step in the procedure. In order to enhance flow rate and reduce overall analysis time, several experiments with lower reagent 
concentrations and shorter reaction times are reported (Table 1). These studies have shown that the concentration of the final $\mathrm{MnO}_{2}$ suspension and the reaction time can be substantially reduced without affecting ${ }^{234} \mathrm{Th}$ recovery, but the limits of these reductions have not yet been explored.

In both the $\mathrm{MnO}_{2}$ and $\mathrm{Fe}(\mathrm{OH})_{3}$ co-precipitation techniques, an in-growth correction must be applied for the time elapsed between sample collection and ${ }^{238} \mathrm{U} /{ }^{234} \mathrm{Th}$ separation, e.g. when acidified, spiked seawater is allowed to sit for several hours prior to co-precipitation in order to reach isotopic equilibration (Pike et al. 2005; Rodriguez y Baena et al. 2005) and during the formation of the precipitate. In-growth and decay can be corrected for by applying the following approach:

$$
\begin{aligned}
{ }^{234} \mathrm{Th}\left(\mathrm{t}_{0}\right) & =\mathrm{e}^{\lambda(\mathrm{t} 1-\mathrm{t} 0)} *\left({ }^{234} \mathrm{Th}\left(\mathrm{t}_{2}\right) * \mathrm{e}^{\lambda(\mathrm{t} 2-\mathrm{t} \mathrm{l})}-{ }^{238} \mathrm{U}\left(\mathrm{t}_{0}\right) *\left(1-\mathrm{e}^{-\lambda(\mathrm{t} 1-\mathrm{t} 0}\right)\right) \\
& ={ }^{234} \mathrm{Th}\left(\mathrm{t}_{2}\right) * \mathrm{e}^{\lambda(\mathrm{t} 2-\mathrm{t} 0)}-{ }^{238} \mathrm{U}\left(\mathrm{t}_{0}\right) *\left(\mathrm{e}^{\lambda(\mathrm{t} 1-\mathrm{t} 0)}-1\right)
\end{aligned}
$$

where $t_{0}$ is the time of sample collection, $t_{1}$ is the time of ${ }^{238} U /{ }^{234} T h$ separation (i.e. collection of the precipitate or radiochemical purification), $t_{2}$ is the time of beta counting, ${ }^{234} \mathrm{Th}(\mathrm{t})$ and ${ }^{238} \mathrm{U}(\mathrm{t})$ are the ${ }^{234} \mathrm{Th}$ and ${ }^{238} \mathrm{U}$ activity at time $\mathrm{t}$, and $\lambda$ is the ${ }^{234} \mathrm{Th}$ decay constant. Thus care must be taken to note the exact time of sample collection and of ${ }^{238} \mathrm{U} /{ }^{234} \mathrm{Th}$ separation.

\section{Measurement Techniques}

\subsection{Gamma counting}

Gamma spectroscopy offers two major advantages: individual isotopes can be clearly identified within the energy spectrum and the analysis is non-destructive. Thus crushed or ashed Mn cartridge samples may be counted directly, a procedure that has also been used at sea. The two suitable peaks for quantifying ${ }^{234} \mathrm{Th}$ are $63.2 \mathrm{keV}$ (branching ratio $\sim 4$ ) and $92.4+92.8 \mathrm{keV}$ (branching ratio $\sim 5.5 \%$ ). These low branching ratios result in low gamma counting rates, and hence ${ }^{234} \mathrm{Th}$ detection efficiencies. This may be compensated by larger sample volumes $\left(10^{2}-10^{4} \mathrm{~L}\right.$; see above). Absorption of these low-energy gamma photopeaks by the sample itself is often significant, but this effect can usually be adequately quantified by matrix-matching standards (see section 3.5).

An alternative method for measuring ${ }^{234} \mathrm{Th}$ using gamma detection is based on $20 \mathrm{~L}$ volume samples, in combination with low background, high efficiency well-type germanium detectors developed during the last decade (Schmidt and Reyss 2000). After filtration, particulate ${ }^{234} \mathrm{Th}$ is directly measured by $\gamma$ counting. Dissolved ${ }^{234} \mathrm{Th}$ is co-precipitated with $\mathrm{Fe}(\mathrm{OH})_{3}$ and, after 
radiochemical purification to remove ${ }^{238} \mathrm{U}, \gamma$ counting of a second $\mathrm{Fe}(\mathrm{OH})_{3}$ allows the simultaneous determination of dissolved ${ }^{234} \mathrm{Th}$ and ${ }^{229} \mathrm{Th}$ (which is used as chemical yield tracer, Figure 4). This procedure does not provide the same precision that can be reached with beta counting, and low levels of particulate ${ }^{234}$ Th may reach the limits of detection. But this approach is isotope specific and avoids more intense purification procedures. The radiochemical purification might be avoided altogether by the use of $\mathrm{MnO}_{2}$ instead of $\mathrm{Fe}(\mathrm{OH})_{3}$ for the initial co-precipitation.

\subsection{Beta counting}

Unlike gamma spectroscopy, beta counting has an excellent counting efficiency for ${ }^{234} \mathrm{Th}$. Apparent efficiencies reach almost $100 \%$ when the beta emissions for ${ }^{234} \mathrm{Th}$ (weak beta at $\mathrm{E}_{\max }=0.27 \mathrm{MeV}$ ) and its daughter ${ }^{234 \mathrm{~m}} \mathrm{~Pa}$ (strong beta at $\mathrm{E}_{\max }=2.19 \mathrm{MeV}$ ) are combined and the sample is reduced into a near weightless source via electroplating on a stainless steel disk (Waples et al. 2003). A 5-position beta counter manufactured by RISØ National Laboratories (Roskilde, Denmark) with $10 \mathrm{~cm}$ lead shield has been most commonly used at sea and in the lab.

Beta counting has two major drawbacks: 1) indiscriminate measurement of all betas emitted from a sample, and 2) possible self absorption-induced biases. When used in combination with ion exchange chemistry and other purification techniques, almost all of the beta activity in the sample is derived from ${ }^{234} \mathrm{Th}$ decay. Traditionally, residual non- ${ }^{234} \mathrm{Th}$ beta activity, including internal conversion electrons of the ${ }^{230} \mathrm{Th}$ spike, is absorbed using a thin 13 mg cm${ }^{-2}$ plastic foil sample cover (e.g. Bhat et al. 1969; Amin et al. 1974). When samples are beta counted without purification, e.g. direct counting of suspended particulate material or $\mathrm{MnO}_{2}$ precipitates, beta emission from non- ${ }^{234} \mathrm{Th}$ decay and ${ }^{234} \mathrm{Th}$ self absorption must be taken into account.

Beta counting of filters can only be well calibrated under the following conditions: a) loading is so thin and shallow that self absorption can be neglected, $b$ ) the loading is constant and the self absorption is reproducible (e.g. by using a known amount of $\mathrm{MnO}_{2}$ precipitate), or c) the filter is prepared to form a homogeneous source of radiation and absorption (as in the case of a multiply folded filter). In cases a) and b), the filter can be counted according to Amin et al. (1974) using a standard which has been prepared with exactly the same matrix. Note that these conditions are very restrictive for the weak beta ${ }^{234} \mathrm{Th}$ which is readily absorbed by any particulate matter on the filter. The risk of self absorption induced interferences can be greatly reduced by minimizing the variations in the particulate load on the filter (in $\mathrm{mg} / \mathrm{cm}^{2}$ ) relative to the cover used for beta counting. A somewhat less restrictive condition can be achieved by using a sample cover of $30 \mathrm{mg} \mathrm{cm}^{-2}$, which limits the detection 
to the stronger beta emitter ${ }^{234 \mathrm{~m}} \mathrm{~Pa}$ and is more than twice as thick as that used by Amin et al. (1974). This cover absorbs $\sim 96 \%$ of betas emitted by ${ }^{234} \mathrm{Th}$, but only $\sim 18 \%$ of ${ }^{234 \mathrm{~m}} \mathrm{~Pa}$ betas. Unfortunately, this procedure also reduces beta counting efficiency by roughly a factor of two.

A correction procedure for case c) is described in detail in Rutgers van der Loeff and Moore (1999). This procedure is only valid for correcting self absorption from a single isotope within a homogeneous sample, and thus requires separation of the stronger ${ }^{234 \mathrm{~m}} \mathrm{~Pa}$ from the weaker ${ }^{234} \mathrm{Th}$ betas by using the thicker absorber $\left(30 \mathrm{mg} \mathrm{cm}^{-2}\right)$ described above. The quantification of self absorption then requires four beta measurements: 1) counting immediately after the sample processing is complete, 2) sample after decay, 3) sample after decay on top of a beta source, and 4) the beta source alone. In cases other than a), b) or c), such as filters with large, and hence variable particle loads from a plankton bloom or from coastal environments, self absorption cannot be quantified and ${ }^{234} \mathrm{Th}$ has to be purified prior to beta-counting according to classical wet chemical techniques or measured by gamma spectrometry.

As beta counting is not isotope specific, the possible contribution of other beta emitters must be evaluated. Although $\mathrm{MnO}_{2}$ does not quantitatively co-precipitate $\mathrm{U}$, it does scavenge a suite of other radionuclides that are beta emitting or have beta emitting daughter products, e.g. $\mathrm{Pa}, \mathrm{Ra}, \mathrm{Bi}, \mathrm{Pb}, \mathrm{Y}$, and Ac. Their impact on ${ }^{234} \mathrm{Th}$ measurement is strongly dependent on the environment. For example, in the open ocean ${ }^{234} \mathrm{Th}$ is the major beta emitter that is significantly adsorbed by $\mathrm{MnO}_{2}$. The small contribution of other nuclides can usually be neglected or estimated from repeated beta counts of the sample (see below). In coastal, freshwater, and groundwater systems, however, the situation is much more complicated. Other beta emitting nuclides can not a priori be neglected. The interference of other nuclides has to be quantified and the use of beta detection will usually require classical ion exchange separation.

In open ocean marine systems, there are several ways to minimize interferences associated with other beta emitters in $\mathrm{MnO}_{2}$ precipitates. First and foremost, the precipitate should be washed with distilled water to remove ${ }^{40} \mathrm{~K}$, a major beta emitter in marine systems. Interferences caused by some weak beta emitting radionuclides (Table 2) may be removed by shielding with a sample cover or absorber. Note that shielding strongly reduces the beta signal and consequently larger sample volumes are required. In instances where shielding with absorber is insufficient, e.g. for strong contaminant betas such as ${ }^{214} \mathrm{Bi}$ or ${ }^{212} \mathrm{Bi}$, samples should be counted repeatedly (Buesseler et al. 2001; Waples et al. 2003). A widely used 
procedure is to perform one count as soon as possible after initial collection and a second count after $>5-6$ half lives. This enables to discriminate between ${ }^{234} \mathrm{Th}$ and other long-lived beta emitters or "background activity" present in the sample. This background activity will depend on the concentration of other nuclides (especially ${ }^{226} \mathrm{Ra}$ daughters) which likely change with depth and hydrography. As such, the background must be determined for every sample.

Depending upon counter availability, it is strongly suggested that samples be repeatedly counted at regular intervals in order to confirm that decay rates of ${ }^{234} \mathrm{Th}$ follows the 24.1d half-life. This is especially important during the initial counting soon after collection, as various Ra daughters are often not in secular equilibrium at the time of sampling. Although ${ }^{226} \mathrm{Ra}$ activity is appreciable even in seawater (Table 2 ), most of the intermediate ${ }^{222} \mathrm{Rn}$ is lost from the $\mathrm{MnO}_{2}$ precipitate during beta measurement, thus reducing the background by an order of magnitude (Benitez-Nelson et al. 2001).

\subsection{Liquid Scintillation counting}

Pates et al. (1996) developed a method for the determination of ${ }^{234} \mathrm{Th}$ in seawater by liquid scintillation spectrometry (LSS). After addition of ${ }^{230} \mathrm{Th}$ as a yield tracer, Th is coprecipitated with $\mathrm{Fe}(\mathrm{OH})_{3}$ and purified through ion exchange chromatography to remove $\mathrm{Fe}$ and U. Smith et al. (2004) recently applied this method and reported that the correction for ${ }^{234} \mathrm{Th}$ in-growth due to co-precipitation of ${ }^{238} \mathrm{U}$ is very low if the amount of $\mathrm{Fe}^{3+}$ used is small, typically less than $1 \%$ of the total ${ }^{234}$ Th activity. After further purification to reduce the presence of chloride ions, a final $0.1 \mathrm{M} \mathrm{HCl}$ solution is mixed with LSS cocktail that is specific for alpha/beta separation. Using modern LSS detectors, alpha and beta emissions can be readily differentiated by pulse shape analysis (PSA) in low quenching conditions, facilitating the use of ${ }^{230} \mathrm{Th}$ as a yield tracer. Given the low backgrounds and high detection efficiencies for ${ }^{234} \mathrm{Th}(\geq 50 \%$ ), this methodology can be used for samples of $\sim 10-20 \mathrm{~L}$, with counting times of about $400 \mathrm{~min}$. Pates et al. (1996) reported detection limits between 0.025 and $0.04 \mathrm{dpm} \cdot \mathrm{L}^{-1}$.

Kersten et al. (1998) used a similar approach with the major difference being that the initial precipitation was conducted using biogenic silica frustules (diatomite) that scavenge ${ }^{234} \mathrm{Th}$ from the water sample. This procedure avoids precipitation of $\mathrm{U}$ and $\mathrm{Fe}$, and thus simplifies the purification of ${ }^{234} \mathrm{Th}$ prior to LSS counting. Precipitation could also be performed using $\mathrm{MnO}_{2}$, which would also avoid the presence of ${ }^{238} \mathrm{U}$ in the precipitate. 
A major advantage of using LSS is the avoidance of separate alpha and beta measurements to determine ${ }^{234} \mathrm{Th}$ activities. Radiochemical purification procedures are similar or even less involved than those commonly required by gas proportional counting. Also, scintillation counters can easily be used at sea. Despite this, few studies have applied this approach (i.e. Foster and Shimmield 2002; Smith et al. 2004). This is likely due to the fact that backgrounds are usually higher and standardization across different quench levels is difficult.

\subsection{Internal standards: selection of the yield monitor}

Many studies of ${ }^{234} \mathrm{Th}$ rely on the use of an internal standard: a spike of known activity that is added to the sample at the start of radiochemical purification to monitor chemical recovery or yield. In principle, any isotope of thorium besides ${ }^{234} \mathrm{Th}$ (e.g. ${ }^{228} \mathrm{Th} ;{ }^{229} \mathrm{Th} ;{ }^{230} \mathrm{Th}$, and ${ }^{232} \mathrm{Th}$ ) may be used as a yield tracer depending on the methodology and instrumentation available and the regime of interest. ${ }^{232} \mathrm{Th}$ should be avoided because of the risk of cross contamination by ${ }^{232} \mathrm{Th}$ and its daughters. Among other Th isotopes, ${ }^{230} \mathrm{Th}$ is the only one that does not lead to significant in-growth of alpha and beta emitting radionuclides in the sample. Thus, even though it is possible to correct for the beta-contribution generated by ${ }^{228} \mathrm{Th}$ and ${ }^{229} \mathrm{Th}$ short-lived daughters (e.g. ${ }^{212} \mathrm{~Pb}$ in the ${ }^{228} \mathrm{Th}$ series and ${ }^{225} \mathrm{Ra}$ in the ${ }^{229} \mathrm{Th}$ series), as shown by Waples et al. (2003), ${ }^{230} \mathrm{Th}$ is recommended (Bhat et al. 1969).

In the "single tracer" method, ${ }^{230} \mathrm{Th}$ is added directly to an acidified liquid sample $(\mathrm{pH} \leq$ 2) and allowed to equilibrate for more than 4 hours. Samples are subsequently purified using ion-exchange chromatography or organic extraction and electroplated onto stainless steel disks (Bhat et al. 1969) or co-precipitated $\left(\mathrm{NdF}_{3}\right)$ and collected onto membrane filters (Rodriguez y Baena et al. 2005); disks and filters are then counted directly for both alpha $\left({ }^{230} \mathrm{Th}\right)$ and beta $\left({ }^{234} \mathrm{Th}\right)$ decay. In the $\mathrm{MnO}_{2}$ co-precipitation technique either this "single tracer" (Rodriguez y Baena et al. 2005) or a "double tracer" approach may be utilized (Pike et al. 2005; Rodriguez y Baena et al. 2005). In the double tracer method, ${ }^{230} \mathrm{Th}$ is used to trace the ${ }^{234} \mathrm{Th}$ scavenging efficiency of the $\mathrm{MnO}_{2}$ co-precipitation, and a second spike $\left({ }^{228} \mathrm{Th}\right.$ or ${ }^{229} \mathrm{Th}$ ) is added to trace the recovery of ${ }^{230} \mathrm{Th}$ during purification, which can then be performed later. In this two tracer approach the chemical recovery of $\mathrm{MnO}_{2}$ co-precipitation, and thus the percentage of ${ }^{234} \mathrm{Th}$ initially present in the sample relative to that actually beta counted, can be estimated according to the following formula:

$$
{ }^{234} \mathrm{Th}_{\text {yield }}={ }^{230} \mathrm{Th}_{\text {net }} *\left({ }^{228} \mathrm{Th}_{\text {net }}\right)^{-1 *}{ }^{228} \mathrm{Th}_{\text {spike }} *\left({ }^{230} \mathrm{Th}_{\text {spike }}\right)^{-1} * 100 \quad \text { Eq. } 3
$$


where ${ }^{228} \mathrm{Th}_{\text {net }}$ and ${ }^{230} \mathrm{Th}_{\text {net }}$ are the ${ }^{228} \mathrm{Th}$ and ${ }^{230} \mathrm{Th}$ net count rates determined by alphaspectrometry $\left(\mathrm{s}^{-1}\right)$ or ICP-MS (cps), ${ }^{228} \mathrm{Th}_{\text {spike }}$ and ${ }^{230} \mathrm{Th}_{\text {spike }}$ are the ${ }^{228} \mathrm{Th}$ and ${ }^{230} \mathrm{Th}$ spiked activities (in Bq; $1 \mathrm{~Bq}=60 \mathrm{dpm}$ ), and ${ }^{234} \mathrm{Th}_{\text {yield }}$ is the ${ }^{234} \mathrm{Th}$ chemical recovery (\%). This same formula is applicable to the single tracer approach by simply deleting the ${ }^{228} \mathrm{Th}$ terms and multiplying by a cpm to dpm correction factor (Rodriguez y Baena et al. 2005)

While ${ }^{230} \mathrm{Th}$ is often favored because it is a pure alpha emitter, Waples et al. (2003) argue that ${ }^{229} \mathrm{Th}$ is a preferable yield monitor for freshwater samples. First, the activity of ${ }^{230} \mathrm{Th}$ can be quite high in freshwater environments. For example, the ${ }^{230} \mathrm{Th}$ activity in Lake Michigan surface sediments is approximately $0.7 \mathrm{dpm} \mathrm{g}^{-1}$ and approximately the same activity can be expected in resuspended material in the water column. Thus, substantial activities of ${ }^{230} \mathrm{Th}$ would be required to dilute any small variation in the ambient ${ }^{230} \mathrm{Th}$ signal or a second sample would need to be analyzed specifically for ambient ${ }^{230} \mathrm{Th}$. Second, approximately 23 $\%$ of all ${ }^{230} \mathrm{Th}$ disintegrations emit an internal conversion electron. These electrons must either be shielded (thereby reducing the signal strength of ${ }^{234} \mathrm{Th}$ ) or separated into the background beta count by repeatedly counting the sample (i.e., a multiple beta count, see Buesseler et al. 2001).

Beta emitting progeny from ${ }^{229} \mathrm{Th}$, on the other hand, can be quantified and subtracted from the gross beta count using the beta contribution approach of Waples et al. (2003). The issue of ${ }^{229}$ Th progeny contaminating alpha detectors is not particularly severe and moreover it can be minimized by application of "recoil prevention" techniques (e.g. Sill and Olson, 1970). ${ }^{225} \mathrm{Ra}$, the longest-lived daughter of ${ }^{229} \mathrm{Th}$ with alpha-emitting progeny, has a half-life of only 15 days. In addition, none of the alpha-emitting daughters of ${ }^{229}$ Th have energies that interfere with the alpha spectra of any of the thorium or uranium nuclides. Moreover, ${ }^{229} \mathrm{Th}$ is a gamma emittor and the recent development of low-background - high efficiency gamma spectrometers allows now the simultaneous determination of the ${ }^{229} \mathrm{Th}$ yield tracer and of ${ }^{234} \mathrm{Th}$ in seawater (Schmidt and Reyss 2000).

\subsection{Detector Calibration}

An external calibration is based on a simple principle: the signal intensity of an element in an unknown material can be determined using the signal intensity of the same element of a known concentration in another material (external standard). An appropriate standard for beta and gamma measurements must have a matrix and geometry that is as close as possible to those of the sample, in order to match the counting efficiency and the self absorption of the 
radiation emitted by the sample. Ideally, one should use a certified reference material with a matrix that matches the one of the sample. Unfortunately, ${ }^{234} \mathrm{Th}$ certified reference materials with the same physical, chemical characteristics of collected samples are difficult and sometimes impossible to obtain from commercial suppliers. As a result, internal laboratory standards are often used instead. This is usually achieved by homogeneously spiking a known amount of standard solution into a sample matrix and geometry similar to those of the samples to be measured. Such external standards can be prepared with either high/artificial (hundreds of dpm) or low/natural ( dpm) activities. High activity sources have the advantage of minimizing instrumental background and procedural blanks, while enabling the rapid attainment of satisfactory counting statistics (thus allowing for routine calibration). When using high-activity ${ }^{238} \mathrm{U} /{ }^{234} \mathrm{Th}$ standards, one should be aware of memory effects of the counter, which have sometimes been observed to last for hours and may be due to recoil and depend on the integrity of the foil used to cover the spike. Some crosstalk to neighbouring counters has been observed by several workers, but this was limited to approx $0.01-0.03 \%$ of the spike count rate, or an additional count rate of just $0.05 \mathrm{cpm}$ on a position next to a 150 $300 \mathrm{cpm}$ spike. We do not know the reason for this very small effect. It should be realized that sources of other beta emitters like ${ }^{99}$ Tc have a different energy spectrum. They cannot be used for counter calibration or even for the determination of relative counter efficiencies for ${ }^{234} \mathrm{Th}$.

$\mathrm{MnO}_{2}$ cartridges are typically ashed and counted using gamma detectors. Given the wide number of researchers who use this technique we describe the protocol for making a standard for an ashed $\mathrm{MnO}_{2}$ cartridge as follows. Homogenize $\mathrm{MnO}_{2}$ cartridge ash $(\sim 20 \mathrm{~g})$ in a ceramic mortar and add a weighed amount (e.g. corresponding to $2000 \mathrm{dpm}$ ) of ${ }^{238} \mathrm{U}$ standard solution with ${ }^{234} \mathrm{Th}$ in secular equilibrium. Rinse the weighing container and pipette thrice with acid having the same molarity as the ${ }^{238} \mathrm{U}$ standard solution. Dry the spiked powder at $50^{\circ} \mathrm{C}$ until a constant weight is achieved ( $\geq 48$ hours for $20 \mathrm{~g}$ of standard powder) and repeat the homogenization. In well-type Ge detectors, the same counting vial can be calibrated for various geometries (e.g. sample heights) using different amounts of standard material.

As mentioned earlier, low-energy beta radiation is especially sensitive to selfabsorption induced attenuation. The extent of self absorption can be determined in individual samples or for a reproducible sample geometry, such as that found in a filter with constant particle or $\mathrm{MnO}_{2}$ loading (Rutgers van der Loeff and Moore 1999). As in the case of gamma spectrometry, the availability of standards in the appropriate sample geometries for beta 
calibration is poor to none. Here, we present several examples of how to prepare standards for ${ }^{234} \mathrm{Th}$ determination by beta counting.

In open ocean studies, deep water samples are often used for calibration as it is assumed that they are in equilibrium between ${ }^{234} \mathrm{Th}$ and its parent ${ }^{238} \mathrm{U}$. This option is not available in coastal waters where ${ }^{234} \mathrm{Th}$ is depleted throughout the water column, or in the few hundred meter above the seafloor where ${ }^{234} \mathrm{Th}$ may be affected by sediment resuspension (Bacon and Rutgers van der Loeff 1989). In the open ocean, excess (Usbeck et al. 2002; Savoye et al. 2004) and depletion (Coppola et al. 2005) in ${ }^{234}$ Th activity relative to ${ }^{238} \mathrm{U}$ have been reported in waters as deep as $500 \mathrm{~m}$, while depletion in bottom waters has been observed until $500 \mathrm{~m}$ above the seafloor, a disequilibrium that was likely due to lateral advection (Turnewitsch and Springer 2001). We consider mid-water samples (2000 - $3000 \mathrm{~m}$ ) suitable for calibration, provided the water samples are taken from substantially above the bottom nepheloid layers.

As a good alternative to freshly collected deepwater, we suggest preparation of standards using either aged seawater or a standard ${ }^{238} \mathrm{U}$ solution or uranium oxide. Aged filtered seawater should be acidified $(\mathrm{pH} \leq 2)$ immediately after collection to avoid adsorption and stored for $>6$ months. This water should then be processed in exactly the same way as the samples to be beta counted $\left({ }^{234} \mathrm{Th}\right.$ in secular equilibrium with ${ }^{238} \mathrm{U} ;{ }^{238} \mathrm{U}$ measured by alpha spectrometry or ICP-MS). A standard ${ }^{238} \mathrm{U}$ solution (with ${ }^{234} \mathrm{Th}$ in secular equilibrium) may also be spiked onto filters containing particles or the $\mathrm{MnO}_{2}$ precipitate. If neither aged seawater or a standard ${ }^{238} \mathrm{U}$ solution is available, we recommend the gravimetric addition of a $\mathrm{U}_{3} \mathrm{O}_{8}$ compound to filters mounted in the same geometry as the samples.

\subsection{Other approaches and future techniques}

\subsubsection{Cerenkov}

Cerenkov radiation offers a completely different approach for the measurement of ${ }^{234} \mathrm{Th}$. Cerenkov radiation is generated when a charged particle travels through a liquid at a velocity (v) in excess of the speed of light (c):

$$
\mathrm{v}>\mathrm{c} / \mathrm{n}
$$

where $\mathrm{n}$ is the refractive index of the liquid. For beta radiation in water, this condition is met for electrons with an energy in excess of the Cerenkov threshold energy, $0.256 \mathrm{MeV}$. 
Approximately 225 photons are produced for every $\mathrm{cm}$ that the electron travels until its energy falls below $0.256 \mathrm{MeV}$.

Beta decay has a continuous energy spectrum up to a maximum energy $\mathrm{E}_{\max }$. The decay of ${ }^{234} \mathrm{Th}\left(\mathrm{E}_{\max }=0.27 \mathrm{MeV}\right)$ is too weak to produce Cerenkov radiation, but the decay of ${ }^{234 \mathrm{~m}} \mathrm{~Pa}\left(\mathrm{E}_{\max }=2.19 \mathrm{MeV}\right)$ is strong enough (Table 3). This measurement technique has recently been used for the quantification of ${ }^{234} \mathrm{Th}$ after purification (Morris et al. 1994; Nour et al. 2002). A major advance would be the ability to measure and identify Cerenkov radiation of ${ }^{234 \mathrm{~m}} \mathrm{~Pa}$ in situ. We have explored (in cooperation with Dr Bosetti, Aachen University) whether this is possible. With large photomultipliers measuring in coincidence mode, we were able to detect the ${ }^{234 \mathrm{~m}} \mathrm{~Pa}$ radiation. However, a major problem is the presence of ${ }^{40} \mathrm{~K}$, which has an activity 290 times higher in seawater than ${ }^{238} \mathrm{U}$ and its daughters. In principle, these isotopes can be separated because ${ }^{40} \mathrm{~K}$ betas have a lower energy (Table 3). If the photons are measured with high enough efficiency, those events that produce $>130$ photons must be due to ${ }^{234 \mathrm{~m}} \mathrm{~Pa}$ (or to the much less abundant ${ }^{214} \mathrm{Bi}$ ). Unfortunately, we were unable to achieve sufficient photon recovery to allow reliable separation of ${ }^{234 m} \mathrm{~Pa}$ from ${ }^{40} \mathrm{~K}$. Nonetheless, we feel that a system where seawater is pumped through a dark sphere surrounded with photomultipliers in coincidence mode, should be investigated. The ${ }^{40} \mathrm{~K}$ signal, corrected for salinity, could serve as calibration for light absorption by particles or dissolved matter, but the construction of such a device remains a challenge.

\subsubsection{Automation}

At the start of the Joint Global Ocean Flux Study (JGOFS) project, Moore (1990) made a strong and compelling argument for the automation of trace geochemical sampling. He proposed a concept for an automated ${ }^{234} \mathrm{Th}$ data logger based on thin pads of $\mathrm{MnO}_{2}$ fiber attached to a long belt. Seawater would flow through the fiber, which would then be directly counted using a beta counter. Although this concept was never realized, it provided inspiration for an automated ${ }^{234} \mathrm{Th}$ analyzer that has recently been built (Rutgers van der Loeff et al. 2004).

This system (Figure 5) follows the small volume technique (section 2.3): it performs filtration of $5 \mathrm{~L}$ of seawater and the subsequent co-precipitation of dissolved ${ }^{234} \mathrm{Th}$ with $\mathrm{MnO}_{2}$ onto a second filter. The filter holders fit into a 10-position beta counter. This system may be used for automatic sampling and analysis on surface water transects, thus producing data on the horizontal distribution of export production. 


\section{Sources of errors and approaches to reduce the uncertainties.}

\subsection{Volume measurements}

Sample volume measurements are required at numerous steps in the collection of ${ }^{234} \mathrm{Th}$, from the time of collection to adding the yield monitor. Thus, all volume measurements must be performed with the greatest degree of precision $(<1 \%)$. One of the best ways to achieve this is to measure the sample through weighing. Weighing on board ship is difficult, but possible with a mechanical balance (as opposed to weighing with a scale based on measuring force), the reproducibility is typically $<0.15 \%$ for $20 \mathrm{~kg}$ samples. Alternatively, adequate containers may be prepared and calibrated for a specific volume, preferably using weight. For volumes ranging from 5 to $2000 \mathrm{~mL}$, high-precision volumetric flasks are recommended, as their precision is excellent (e.g. $\leq 0.5 \%$ for $5 \mathrm{~mL}, \leq 0.16 \%$ for $25 \mathrm{~mL}, \leq 0.05 \%$ for $500 \mathrm{~mL}$ ). For the $4 \mathrm{~L}$ method, bottles are calibrated in advance by weight, such that when filled to a constant height, precision is $<0.1 \%$. The volume passing an in-situ pump is most reliably measured by a positive displacement flow meter.

\subsection{Particulate ${ }^{234}$ Th: sampling, analysis and associated biases}

Several techniques have been used to collect settling or suspended particles (Table 4). Filtration is an operational procedure that can be influenced by many factors, filter loading or clogging, pressure gradients, matrix, active avoidance by zooplankton (e.g. Liu et al., 2005) and sorption of dissolved components. Most of these issues are not unique to ${ }^{234} \mathrm{Th}$ and many of these problems are described and compared in Buesseler et al. (2005). Here we concentrate on post processing and ${ }^{234} \mathrm{Th}$ measurement techniques.

The collection of particulate ${ }^{234} \mathrm{Th}$ is confounded by the types of filters that are ultimately used to collect the particulate ${ }^{234} \mathrm{Th}$ fraction. Historically, the majority of studies of particulate ${ }^{234}$ Th use glass fiber filters (GFFs, nominal pore size $<0.7 \mu \mathrm{m}$ ) or Quartz Microfiber (QMA, nominal pore size $<1.0 \mu \mathrm{m}$ ) filters. In the open ocean, these filters can be used to process relatively large volumes of water without clogging and they enable the measurement of ${ }^{234} \mathrm{Th}$ and other elements, such as $\mathrm{C}$ and $\mathrm{N}$, on the exact same filter. The recent move to QMAs is the result of a lower radioactivity blank with direct beta counting, presumably due to a decrease in ${ }^{40} \mathrm{~K}$ levels (e.g. Buesseler et al. 2001). Please note that coastal applications will still suffer from calibration issues associated with variable particle loading (see section 3.2).

Unfortunately, evidence suggests that both GFFs and QMAs adsorb dissolved ${ }^{234} \mathrm{Th}$. Benitez-Nelson et al. (2001) and Buesseler et al. (1998) showed that this effect was largest 
with small sample volumes (30-50 L as opposed to 300-500 L) and low flow rates. New evidence confirms this effect. In the North Pacific Subtropical Gyre, small volume particle samples (2 - 25 L) taken at $150 \mathrm{~m}$ below the surface were collected onto QMA, Nuclepore and Silver filters (Ag, nominal pore size $<1.2 \mu \mathrm{m})$ and compared. Each filter was stacked in sets of two so that the first filter collected "particles" and the second "blank" filter, placed directly underneath, monitored adsorption of dissolved ${ }^{234} \mathrm{Th}$. There was a significant correlation between low volume, high ${ }^{234} \mathrm{Th}$ particle activities for the QMA filters, with QMAs $~ 50 \%$ higher relative to the Ag and Nuclepore samples (Figure 6, Benitez-Nelson unpublished data).

Why does ${ }^{234}$ Th adsorb to GFFs and QMAs and not Ag or Nuclepore filters? It is likely related to the filter composition and matrix, e.g. membrane versus fiber. This issue is not unique to ${ }^{234} \mathrm{Th}$. Moran et al. (1999) found that GFFs will also adsorb a substantial amount of dissolved organic carbon (DOC). As a result, these types of samples may overestimate the amount of particulate organic carbon (POC) by as much as a factor of $2-4$. Given the particle reactivity of ${ }^{234} \mathrm{Th}$ and research that suggests complexation of dissolved ${ }^{234} \mathrm{Th}$ by DOC, it may be this linkage that controls dissolved Th adsorption in various regimes (Santschi et al. this volume). It is also possible that the silica matrix absorbs thorium directly. Burnett et al. (1997) found that actinides were scavenged by silica gel, whereas, as mentioned before, Kersten et al. (1998) used diatomite to scavenge ${ }^{234} \mathrm{Th}$.

Combining all the observations from the above studies suggests that ${ }^{234} \mathrm{Th}$ particle collections using GFF or QMA filters should be conducted from large volumes of seawater (e.g. $>300$ L). If small volumes are processed, then either Ag or Nuclepore filters should be used. Ag filters are preferred if other measurements, such as $\mathrm{C}$ and biogenic silica, are to be conducted as they enable analyses on the same filter. The error introduced by dissolved ${ }^{234} \mathrm{Th}$ adsorption on derived particle concentrations will greatly depend on the area. In the open ocean, where particulate ${ }^{234} \mathrm{Th}$ is low and dissolved ${ }^{234} \mathrm{Th}$ high, the adsorption effect may be quite significant. In the coastal ocean, where ${ }^{234} \mathrm{Th}$ particle activities are generally much higher and dissolved ${ }^{234}$ Th concentrations low due to scavenging, it is likely that absorption will be less of an issue. In order to avoid artifacts associated with post collection particle exchange processes, we strongly recommend that particle filtration be conducted as soon as possible after collection as dissolved Th may adhere to sample bottle walls (Benitez-Nelson et al. 2001) or particulate Th may decrease with time in stirred samples within just a few hours after sample collection. 
Once collected, particulate samples are usually counted using non-destructive beta or gamma counting since it allows the measurement of other chemical constituents, such as $\mathrm{C}, \mathrm{N}$ and $\mathrm{Si}$, on the exact same filter measured for ${ }^{234} \mathrm{Th}$. This avoids variability between individual samples or filter types. Furthermore, it enables counting the filters on board ship. This is often mandatory when particle concentrations are low and the cruise duration is long, conditions which often occur in many open ocean studies. Samples obtained with a flow-through centrifuge (e.g. Schüßler and Kremling 1993) or sediment trap can be gamma-counted without any preparation provided sufficient material has been collected. Size-fractionated suspended particles are usually collected with in-situ pumps or on deck (Trull and Armand 2001) using nitex screens. Material rinsed off these screens as well as small amounts of sediment trap material can be collected on filters, such as polycarbonate, glass, quartz or silver depending on the element of interest and the ${ }^{234} \mathrm{Th}$ background (see Table 4). Beta counting is more sensitive, but self absorption may be difficult to quantify (see section 3.2), thus making gamma counting sometimes preferable or wet chemistry necessary.

\subsection{U-salinity relationship}

Regardless of the model used, estimating ${ }^{234}$ Th export fluxes necessitates knowledge of ${ }^{238} \mathrm{U}$ activities (Savoye et al. 2005). The oceanic cycle of $U$ is considered to be in steady state with a residence time of $\sim 400 \mathrm{kyr}$, substantially longer than the mean ocean-mixing time $(\mathrm{Ku}$ et al. 1977; Dunk et al. 2002). Under oxic conditions, dissolved U in seawater occurs dominantly as the stable uranyl carbonate ion $\mathrm{UO}_{2}\left(\mathrm{CO}_{3}\right)_{3}{ }^{4-}$ and is conservative with salinity (Ku et al. 1977). As a result, ${ }^{238} \mathrm{U}$ activities are typically determined from salinity using the average uranium $\left({ }^{238} \mathrm{U}+{ }^{235} \mathrm{U}\right)$ concentration in seawater of $3.238 \mathrm{ng} / \mathrm{g}$ normalized to a salinity of 35 (Chen et al. 1986), which is equivalent (at a salinity of 35) to a mean seawater ${ }^{238} \mathrm{U}$ activity of $2.40 \mathrm{dpm} \mathrm{kg}{ }^{-1}$. At $10^{\circ} \mathrm{C}$, using a density of $1.027 \mathrm{~kg} \mathrm{~L}^{-1}$, this corresponds to the often used relationship: ${ }^{238} \mathrm{U}\left(\mathrm{dpm} \mathrm{L}{ }^{-1}\right)=0.0704$ x Salinity.

This relationship may even hold at low salinities (e.g. Andersson et al. 1995; Feng et al. 1999). But non conservative $U$ behavior has also been reported in a wide range of oceanic regions (Figure 7). This may be due to $\mathrm{U}$ precipitation and removal in suboxic or anoxic marine basins, such as the Black Sea (Anderson et al. 1989), the Baltic Sea (Löfvendahl 1987), the Arabian Sea (Rengarajan et al. 2003) or North-European fjords (Todd et al. 1988). The highly reactive nature of all $U$ phases on the Amazon shelf and in estuaries also suggests that remobilization and fractionation of $U$ may occur in river-influenced coastal environments (McKee et al. 1987; Barnes and Cochran 1993; Balakrishna et al. 2001). Robinson et al. 
(2004) observed slightly higher values, in the waters of the Bahamas (western Equatorial Atlantic) compared to Chen et al. (1986).

In rivers, $\mathrm{U}$ concentrations vary widely around an average of $1.3 \mathrm{nmol} \mathrm{L}^{-1}$ (Palmer and Edmond 1993; Windom et al. 2000) but in some Asian rivers (Ganges, Yellow river) the U content exceeds that in seawater (Palmer and Edmond 1993). A summary of ${ }^{238} \mathrm{U}$ activities versus conductivity in North American lakes, bogs, and rivers is presented in Waples et al. (2003) and estuarine behavior is summarized by Swarzenski et al. (2003). These studies suggest that care must be taken when using the U-salinity relationship (Chen et al. 1986), particularly at low salinities, when variable, non-zero river concentrations and possible nonconservative behavior can occur.

\subsection{Basic statistics and propagation of errors}

Whenever experimental data is used in the computation of a derived quantity, precision must be considered (Friedlander et al. 1981). According to EURACHEM-CITAC recommendations (EURACHEM/CITAC-Guide 1995), the process of analytical uncertainty estimation should proceed as follows: 1) specify the relationship between measured parameters, 2) identify uncertainty sources, 3) quantify uncertainty components, and 4) calculate the total uncertainty. Total uncertainty should be computed according to basic rules of error propagation (Zar 1996). The variance for four of the elementary arithmetic operations are given by:

$$
\begin{array}{lll}
\mathrm{x}=\mathrm{a} u \pm \mathrm{b} v & \sigma_{\mathrm{x}}{ }^{2}=\mathrm{a}^{2} \sigma_{u}{ }^{2}+\mathrm{b}^{2} \sigma_{v}{ }^{2} & \text { Eq. } 5 \\
\mathrm{x}= \pm \mathrm{a} u v \text { or } \pm \mathrm{a} u / v & \sigma_{\mathrm{x}}{ }^{2} / \mathrm{x}^{2}=\sigma_{u}{ }^{2} / u^{2}+\sigma_{v}{ }^{2} / v^{2} & \text { Eq. } 6
\end{array}
$$

where $\mathrm{x}$ is the calculated variable, " $\mathrm{u}$ " and "v" are the measured variables, " $a$ " and "b" represent constants and $\sigma$ is the standard deviation associated with each variable.

For ${ }^{234}$ Th measurements, uncertainties will depend upon the procedure applied and the detection technique selected. In general, sources of uncertainty that need to be recognized include those associated with volume measurements (sample and tracer spikes), counting efficiency, chemical recovery, detector background and blank activity. Each of these uncertainties encompasses all related computation uncertainties. For example, the determination of counting efficiency takes into account propagation of the uncertainty on count rates, spike volume and the known standard activity. In the case of non-destructive beta-counting, this includes uncertainties associated with non ${ }^{234}$ Th decay (see section 3.2 ) 
which is typically taken into account using multiple beta counts (Buesseler et al. 2001). In a similar approach discussed by Rodriguez y Baena et al. (2005), uncertainties are derived from a plot of raw counting rates versus time. A weighed least squares regression line is fit using $\mathrm{e}^{-}$ ${ }^{\lambda t}$, where $\lambda$ is the decay constant of ${ }^{234} \mathrm{Th}$ (in $\mathrm{d}^{-1}$ ) and $\mathrm{t}$ is the time interval (in d) between the midpoint of sampling and counting. Initial ${ }^{234} \mathrm{Th}$ activity is estimated as the slope of the regression line with the y-intercept as the background. In order to validate the quality of the estimates, it is suggested to run a "Reduced $\chi^{2}$ Test" on each set of repeated counts. Errors are propagated from counting statistics, based upon the fit to the raw counts. If one considers an average beta counter background of $0.15-0.20 \mathrm{cpm}$ (typical for most RIS $\varnothing$ beta counters) and a procedural blank of the same order of magnitude, ${ }^{234} \mathrm{Th}$ activities as low as a few tenths of a dpm may be quantified.

\section{Sampling and measurement guidelines}

\subsection{General considerations}

Sampling procedures used for ${ }^{234} \mathrm{Th}$ analysis range from discrete sampling (from as small as $2 \mathrm{~L}$ in the open ocean to perhaps $>200 \mathrm{~L}$ in freshwater environments) to in situ filtration and collection of ${ }^{234} \mathrm{Th}$ on filter cartridges from large volume samples ( $\left.>1000 \mathrm{~L}\right)$. The choice depends on the questions one wishes to answer. The determination of the export flux of ${ }^{234} \mathrm{Th}$ requires the integrated depletion of total ${ }^{234} \mathrm{Th}$ in the surface water. For this purpose, one does not need a separate determination of particulate ${ }^{234} \mathrm{Th}$, but rather total ${ }^{234} \mathrm{Th}$ at high vertical resolution. The small volume technique is very well suited for this purpose. In situ pumps cannot reach the same accuracy and it is logistically much more demanding to achieve the same resolution.

If the focus is on particle dynamics, the small volume technique is not appropriate due to long counting times. Typically, if $\sim 10 \%$ of Th is in the particulate phase, and $\sim 1 \mathrm{dpm} \mathrm{L} \mathrm{L}^{-1}$ is the total ${ }^{234} \mathrm{Th}$ concentration, then a $2-5 \mathrm{~L}$ sample will only contain $0.2-0.5 \mathrm{dpm}$ of particulate ${ }^{234} \mathrm{Th}$, a challenge to measure precisely with a beta counter. The $20 \mathrm{~L}$ technique has been used routinely for the analysis of particulate ${ }^{234} \mathrm{Th}$, even in deep ocean water (e.g. Rutgers van der Loeff et al. 2002).

Whereas the export flux of ${ }^{234} \mathrm{Th}$ can be calculated through ${ }^{234} \mathrm{Th} /{ }^{238} \mathrm{U}$ disequilibria alone, the determination of the export flux of other components requires the knowledge of the ratio of this component to ${ }^{234} \mathrm{Th}$ in the export flux (Buesseler et al. 2005; Savoye et al. 2005). As larger particle sizes are thought to be primarily responsible for the export flux, we need ${ }^{234} \mathrm{Th}$ data and chemical analysis of sinking particles and/or particles of various size fractions. 
This size fractionating filtration requires larger volumes that can usually only be handled with in situ pumping or other techniques such as split flow-thin cell fractionation (SPLITT, Gustafsson et al. 2000; 2005). The same holds true if ${ }^{234} \mathrm{Th}$ is to be used for the study of exchange between various particle size groups.

If ${ }^{234} \mathrm{Th}$ is measured to derive export fluxes, then for small ${ }^{234} \mathrm{Th}$ depletions, the highest precision is required (cf. Coale and Bruland 1987). Sample volume and/or counting time should be adapted to the required propagated error in the integrated depletion. In view of the uncertainties with the $\mathrm{MnO}_{2}$ coated cartridge technique (see section 2.2), it is hard to achieve sufficient precision with in-situ pumping. The best strategy may be to determine small disequilibria between ${ }^{238} \mathrm{U}$ and ${ }^{234} \mathrm{Th}$ with high-resolution small volume sampling in conjuction with size-fractionated particulate $\mathrm{C} /{ }^{234} \mathrm{Th}$ ratios determined on separate pump casts.

\subsection{Coastal versus open ocean conditions}

Developments in ${ }^{234} \mathrm{Th}$ methodology have largely been driven by the specific needs of the oceanographic community. Some of the greatest challenges have been the accurate determination of small ${ }^{234} \mathrm{Th} /{ }^{238} \mathrm{U}$ disequilibria, the need to increase sample throughput and the ability to measure sample ${ }^{234} \mathrm{Th}$ activities while at sea for extended periods. These issues are not necessarily true for coastal and freshwater samples where activities and interferences are very different. For example, a lower $U$ content in freshwater relative to seawater implies that larger sample volumes are required to determine ${ }^{234}$ Th activities. Furthermore, coastal seas usually have higher particle loads resulting in stronger scavenging and even lower dissolved ${ }^{234} \mathrm{Th}$ activities. Calibration is more difficult as there is usually no depth where one can assume ${ }^{234} \mathrm{Th}$ to be in equilibrium with ${ }^{238} \mathrm{U}$ (e.g. Coppola et al. 2002). Hence, calibration with freshly collected deep water samples is impossible during expeditions in coastal seas. The interference of humic material is absent in the open ocean, but also may be problematic in coastal and freshwater systems. We observed that the production of a $\mathrm{MnO}_{2}$ precipitate in filtered coastal waters (Lake Grevelingen, the Netherlands) caused major coagulation, affecting the direct beta counting technique. We ascribe this coagulation to the presence of humic material in this enclosed environment (see section 2.2).

\subsection{Freshwater systems}

Few measurements of ${ }^{234} \mathrm{Th}$ have been made in freshwater systems (Table 5), but several methods for measuring ${ }^{234} \mathrm{Th}$ activities in freshwater lakes, rivers and groundwater 
exist. The purpose of this section, therefore, will be to examine some of the factors involved in choosing a method as well as examine how recent developments in ${ }^{234} \mathrm{Th}$ methodology may or may not apply to freshwater lakes, rivers and groundwater.

In marine systems, $\mathrm{MnO}_{2}$ precipitates are currently favored primarily because it does not co-precipitate $\mathrm{U}$. However, $\mathrm{MnO}_{2}$ will scavenge $\mathrm{Ra}$. This often does not pose a serious problem in the open ocean, because ${ }^{234} \mathrm{Th}$ beta activities are much greater than activities generated from $\mathrm{Ra}$ and its progeny. This is not necessarily the case in freshwater or nearshore systems where beta activity related to the decay of ${ }^{228} \mathrm{Ra},{ }^{224} \mathrm{Ra}$ and ${ }^{226} \mathrm{Ra}$ can be as high as that generated by ${ }^{234} \mathrm{Th}$ (Table 2). Because betas emitting from all three Ra isotopes are not at steady state, care needs to be taken on just how the beta counts are interpreted. Moreover, because the beta particles emitted by certain Ra progeny are energetic (e.g. $>1 \mathrm{MeV}$ ), there is no practical way of shielding these betas with thin absorbers. Therefore, while the use of a $\mathrm{MnO}_{2}$ precipitate may indeed prove to be preferable to an $\mathrm{Fe}(\mathrm{OH})_{3}$ precipitate in some situations, it may require either further chemical separation of Ra from Th or separate quantification of each Ra-associated nuclide and its respective contribution to the total beta count. In Lake Michigan, $\mathrm{Fe}(\mathrm{OH})_{3}$ was used to efficiently scavenge ${ }^{234} \mathrm{Th}$ (Waples et al. 2003). When approximately $1 \mathrm{mg}$ of ferrous iron was added for each liter of filtered water, 17 $\pm 2.6 \%$ of the ${ }^{238} \mathrm{U}$ activity was co-precipitated with the ${ }^{234} \mathrm{Th}$. The uncertainty of the scavenged amount of ${ }^{238} \mathrm{U}$ (i.e. $\pm 2.6 \%$ ) was negligible in its effect on ${ }^{234}$ Th-derived particle removal rates because of the large disequilibrium between ${ }^{234} \mathrm{Th}$ and ${ }^{238} \mathrm{U}$ in Lake Michigan. In freshwater systems, sample volume is important as ${ }^{234} \mathrm{Th}$ activities are generally very low (Table 2). If sample volume is of no concern, then gamma counting is possible and in many ways preferable (Dominik et al. 1989; Vogler et al. 1996; Roberts and Santschi 2004). Sample preparation is relatively simple and non-destructive (Rutgers van der Loeff and Moore 1999). Gamma spectrometry will also allow the identification and quantification of individual radionuclides. This is especially critical in freshwater where activity ratios of ${ }^{234} \mathrm{Th}$ relative to other beta-emitting radionuclides are often much lower than those found in marine systems (see Section 3.2). If sample volume is a concern, e.g. due to logistical or sample throughput constraints, then ${ }^{234} \mathrm{Th}$ activities should be measured by beta counting, which is the most sensitive counting technique for this isotope (see Section 3.2). Beta counting is also preferred in aquatic systems with either a high particle load or low activities of ${ }^{234} \mathrm{Th}$. For example, if $1 \mathrm{mg}$ of ferrous iron was added to each liter of sample water following the procedure described by Waples et al. (2003), the large amount of precipitate generated would lead to high self-absorption and a reduction in the ${ }^{234} \mathrm{Th}$ signal. 
While there is no hard and fast rule as to how much water needs to be collected for ${ }^{234} \mathrm{Th}$ analysis, a rough guide for freshwater follows. If 2 to $20 \mathrm{~L}$ of water are sufficient for beta counting ${ }^{234} \mathrm{Th}$ in marine systems, where ${ }^{238} \mathrm{U}$ activities average $\sim 2.3 \mathrm{dpm} \mathrm{kg}$, the same amount of water multiplied by the activity ratio of ${ }^{238} U_{\text {marine }}{ }^{238} U_{\text {freshwater }}$ should be sufficient for beta counting in most systems. The amount of water required for a ${ }^{234} \mathrm{Th}$ measurement by gamma spectroscopy would have to be increased by a minimum of tenfold. Water samples of $100-200 \mathrm{~L}$ were sufficient to measure ${ }^{234} \mathrm{Th}$ in nearshore Lake Michigan waters where median ${ }^{234}$ Th activities were $8 \mathrm{dpm} \mathrm{m}^{-3}$ in the dissolved phase and $61 \mathrm{dpm} \mathrm{m}^{-3}$ in the particle bound phase (Waples et al. 2004). In contrast, water samples in excess of $2000 \mathrm{~L}$ were required in a study examining ${ }^{234} \mathrm{Th}$ activities in a series of holding ponds at the Rocky Flats Environmental Technology Site (RFETS), where particle bound ${ }^{234}$ Th activities ranged from only 9 to $280 \mathrm{dpm} \mathrm{m}^{-3}$ (Roberts and Santschi, 2004). In unique situations (e.g. uranium mine drainage, Cazala et al. 2003) it may be possible to measure ${ }^{234}$ Th by gamma spectroscopy using relatively small water samples $(<10 \mathrm{~L})$. However, this is generally a rare event.

The measurement of particulate ${ }^{234} \mathrm{Th}$ activities in freshwater systems may also be problematic. In the open ocean where particle concentrations are generally low, beta counting of particle-bound ${ }^{234} \mathrm{Th}$ by non-destructive counting techniques is fairly straightforward (Rutgers van der Loeff and Moore 1999; Buesseler et al. 2001; Pike et al. 2005). Freshwater environments, however, present a special problem as large water samples are required due to the low activity of ${ }^{234} \mathrm{Th}$. However, these waters often contain very high concentrations of plankton and resuspended materials. Thus, efficient timely separation of a large amount of sample material requires the use of a large filter to be effective. For example, up to $\sim 0.5 \mathrm{~g}$ of material could be separated in a reasonable amount of time ( $<1$ hour) from 100 to $200 \mathrm{~L}$ of Lake Michigan water using a $293 \mathrm{~mm}$ diameter nitrocellulose filter $(0.45 \mu \mathrm{m}$ pore size, Millipore Waples et al. 2003). Beta counting this amount directly is difficult due to selfabsorption problems. Thus, large particulate samples must be further processed by removing the ${ }^{234} \mathrm{Th}$ from the particles by acid leaching (Waples et al. 2003).

In groundwater systems, the activities of ${ }^{238} \mathrm{U}$ and ${ }^{234} \mathrm{Th}$ are highly variable, and the conventional beta counting method with ${ }^{230}$ Th spike and $\mathrm{Fe}(\mathrm{OH})_{3}$ coprecipitation method has usually been employed (Hussain and Krishanswami, 1980; Krishnaswami et al., 1982; Baskaran et al., 1986). Activities of dissolved ${ }^{234} \mathrm{Th}$ as low as $15 \mathrm{dpm} \mathrm{m}^{-3}$ have been reported and hence we propose using at least $20 \mathrm{~L}$ water sample for ${ }^{234} \mathrm{Th}$ analysis using the beta counting method. The usually relatively higher concentrations of ${ }^{226} \mathrm{Ra}$ and ${ }^{228} \mathrm{Ra}$ in groundwater could result in higher interference from some of the daughter products of these 
nuclides, and appropriate steps need therefore to be taken for avoiding the interference from non- ${ }^{234}$ Th betas.

\section{Summary and Recommendations}

Throughout this paper, we have attempted to describe many of the methodological issues related to sampling ${ }^{234} \mathrm{Th}$ in aquatic systems. The method of choice for sampling and analysis will depend on the environment and on the questions to be answered. For direction in choosing the appropriate ${ }^{234} \mathrm{Th}$ procedure, we have developed a decision flow chart (Figure 8).

For the measurement of dissolved, particulate, and total ${ }^{234} \mathrm{Th}$ we have several recommendations. First and foremost, the validity of the U-Salinity relationship is only appropriate for estimating dissolved ${ }^{238} \mathrm{U}$ in the open ocean, where waters are well oxygenated and removed from freshwater input. In other regimes, i.e. continental shelves, estuaries, marginal or semi-closed seas, and suboxic / anoxic basins, the U concentration must be measured. In the collection and measurement of ${ }^{234} \mathrm{Th}, \mathrm{Mn}$ cartridges and the "cartridge formula" should be used with care. There are persistent problems related to variations in the extraction efficiency of $\mathrm{MnO}_{2}$-coated cartridges. The assumption of a constant extraction efficiency determined by the ratio of two cartridges in series may cause both random and systematic errors in calculated ${ }^{234} \mathrm{Th}$ activity that are highest when the extraction efficiency is lowest, i.e. under conditions of high flow rate and in the presence of high concentrations of humic substances. The factors that cause the observed variations on the relative and absolute extraction efficiencies may be addressed in the future with laboratory experiments and field studies using multiple cartridges and ultrafiltration. As long as these variations cannot be quantified or prevented, the method using the "cartridge formula" should be discouraged if high precision and accuracy are required.

The $\mathrm{MnO}_{2}$ coprecipitation technique should only be applied to unfiltered samples if the self absorption of beta radiation by the particulate fraction on the filter can be neglected or quantified. Yield tracers should be used for the small volume technique unless reproducibility can be maintained e.g. through automation. If no yield tracer is used routinely, it should be checked whether the precipitation efficiency of the sample and of the standard is comparable. This may be an issue when calibrating coastal samples with water from the open ocean. A systematic study on the effects of reduction of reagents and reaction time on thorium recovery should be performed in order to optimize the small volume technique.

When samples are filtered to separate the particulate fraction, the effect of sorption of dissolved ${ }^{234}$ Th onto the filter should be considered, especially in open ocean studies where 
particulate ${ }^{234} \mathrm{Th}$ activities are low. Beta counting of filters can be well calibrated only if a) the loading is small enough that self absorption of ${ }^{234 \mathrm{~m}} \mathrm{~Pa}$ is absent or $\mathrm{b}$ ) the loading is constant and can be reproduced with a standard or $\mathrm{c}$ ) the filter can be prepared to form a homogeneous source of radiation (as in the case of a multiply folded filter) which allows the correction technique described in section 3.2. In other cases there is no way to correct for self absorption of the sample and non-destructive beta counting is not a viable option. We recommend that an intercomparison study be conducted of methods measuring ${ }^{234} \mathrm{Th}$ on particles collected in bottles, in-situ pumps, continuous centrifuge, surface sediment and sediment traps.

Calibration of detectors for various sample types remains a complex issue. In order to standardize the use of "home-made" standards (such as the examples described earlier in this paper, section 3.5), it would be extremely useful to provide the scientific community with a standard operational procedure. A relatively easy method that can be followed by any lab is to process a natural sample of aged acidified filtered (sea)water in which ${ }^{234} \mathrm{Th}$ and ${ }^{238} \mathrm{U}$ have reached secular equilibrium and ${ }^{238} \mathrm{U}$ activity has been determined (by alpha spectrometry or ICP-MS).

Alternatively, one of the best standards for the inter-calibration of ${ }^{234} \mathrm{Th}$ techniques is to use filtered aged deep-ocean water where the activity of ${ }^{238} \mathrm{U}$ is precisely known and the colloidal ${ }^{234}$ Th significantly lower than that found in surface waters. Care must be taken in storing that water, e.g. by acidifying it immediately after collection, to prevent Th absorption onto container walls. Aliquots of this water would then be neutralized to seawater $\mathrm{pH}$ prior to use (Usbeck et al. 2002). Although this method is quite useful for standardizing procedures that use small volumes (less than $20 \mathrm{~L}$ ), large-volume filtration techniques would require the storage of large volumes of deep water. This generates predictable logistical problems. For larger volumes, a standard can be prepared on board by adding a known amount of ${ }^{238} \mathrm{U}$ (which is at secular equilibrium with ${ }^{234} \mathrm{Th}$ ) to a known volume of ${ }^{234} \mathrm{Th}$-free filtered water or to a carefully prepared ${ }^{234} \mathrm{Th}$-free synthetic seawater.

We recommend that a selection of ${ }^{234} \mathrm{Th}$ certified reference materials, such as

$\mathrm{MnO}_{2}\left({ }^{238} \mathrm{U}\right)$ - and $\mathrm{Fe}(\mathrm{OH})_{3}\left({ }^{238} \mathrm{U}\right)$ - partially coated filters (viz. cartridges, QMA and Polycarbonate filters, etc.) be developed and distributed among the oceanographic community

\section{Acknowledgments}

This material was first presented at the FATE (Future Applications of Thorium in the Environment) conference held in August 2004 at WHOI and supported by the U.S. NSF Chemical Oceanography Program (OCE 0354757) in conjunction with the Scientific 
Committee for Oceanographic Research (Working Group \#116). Individuals and science efforts discussed herein were supported by many national science programs, including the U.S. National Science Foundation and U.S. Department of Energy and the Ministerio de Educación y Ciencia of Spain. We thank Kirk Cochran for his helpful comments and Claire Bertoïa for the ${ }^{230} \mathrm{Th}$ analyses and yield calculations of the 4-20 L method comparison. We are grateful for constructive reviews by Bill Burnett and Billy Moore. The Agency is grateful for the support provided to its Marine Environment Laboratory by the Government of the Principality of Monaco". This is AWI contribution nr awi-n15282. 


\section{References}

Amin, B.S., Krishnaswami, S. and Somayajulu, B.L.K., 1974. ${ }^{234} \mathrm{Th} /{ }^{238} \mathrm{U}$ activity ratios in Pacific Ocean bottom waters. Earth Planet. Sci. Lett., 21: 342-344.

Anderson, R.F. and Fleer, A.P., 1982. Determination of natural actinides and plutonium in marine particulate material. Anal. Chem., 54: 1142-1147.

Anderson, R.F., Fleisher, M.Q. and LeHuray, A.P., 1989. Concentration, oxidation state, and particulate flux of uranium in the Black Sea. Geochim. Cosmochim. Acta, 53: 22152224.

Andersson, P.S., Wasserburg., G.J., Chen, J.H., A., P.D. and Ingri, J., 1995. ${ }^{238} \mathrm{U}^{234} \mathrm{U}$ and ${ }^{232} \mathrm{Th}-{ }^{230} \mathrm{Th}$ in the Baltic Sea and in river water. Earth Planet. Sci. Lett., 130: 217-234.

Appelo, C.A.J. and Postma, D., 1999. A consistent model for surface complexation on birnessite $\left(\mathrm{MnO}_{2}\right)$ and its application to a column experiment. Geochim. Cosmochim. Acta, 63: 3039-3048.

Bacon, M.P. and Anderson, R.F., 1982. Distribution of thorium isotopes between dissolved and particulate forms in the deep sea. J. Geophys. Res., 87: 2045-2056.

Bacon, M.P., Huh, C.-A. and Moore, R.M., 1989. Vertical profiles of some natural radionuclides over the Alpha Ridge, Arctic Ocean. Earth Planet. Sci. Lett., 95: 15-22.

Bacon, M.P. and Rutgers van der Loeff, M.M., 1989. Removal of Thorium-234 by scavenging in the bottom nepheloid layer of the ocean. Earth Planet. Sci. Lett., 92: 157-164.

Balakrishna, K., Shankar, R., Sarin, M.M. and Mantjunatha, 2001. Distribution of U-Th nuclides in the riverine and coastal environments of the tropical southwest coast of India. J. Environ. Radioact., 57: 21-33.

Barnes, C.E. and Cochran, J.K., 1993. Uranium geochemistry in estuarine sediments: controls on removal and release processes. Geochim. Cosmochim. Acta, 57: 555-569.

Baskaran, M., Krishnaswami, S. and Bhandari, N. 1986. The geochemistry of uranium and thorium isotopes in the salt lakes and adjacent ground waters of Rajasthan. Journal of Geological Society of India 27, 90-101.

Baskaran, M., Murphy, D.J., Santschi, P.H., Orr, J.C. and Schink, D.R., 1993. A method for rapid in situ extraction and laboratory determination of $\mathrm{Th}, \mathrm{Pb}$, Ra isotopes from large volumes of seawater. Deep-Sea Res., 40: 849-865.

Baskaran, M. and Santschi, P.H., 2002. Particulate and dissolved ${ }^{210} \mathrm{~Pb}$ activities in the shelf and slope regions of the Gulf of Mexico waters. Cont. Shelf Res., 22: 1493-1510.

Baskaran, M., Santschi, P.H., Guo, L., Bianchi, T.S. and Lambert, C., 1996. 234Th:238U disequilibria in the Gulf of Mexico: the importance of organic matter and particle concentration. Cont. Shelf Res., 16: 353-380.

Baskaran, M., Swarzenski, P.W. and Porcelli, D., 2003. Role of colloidal material in the removal of ${ }^{234} \mathrm{Th}$ in the Canada basin of the Arctic Ocean. Deep-Sea Res. I, 50: 13531373.

Benitez-Nelson, C. et al., 2001. Testing a new small-volume technique for determining thorium-234 in seawater. J. Radioanal. Nucl. Chem., 248: 795-799.

Benitez-Nelson, C.R., Buesseler, K.O. and Crossin, G., 2000. Upper ocean carbon export, horizontal transport, and vertical eddy diffusivity in the southwestern Gulf of Maine. Cont. Shelf Res., 20: 707-736.

Bertoïa, C., 2005. ${ }^{234}$ Th-based export flux during the European Iron Fertilization EXperiment in the Southern Ocean, MSc thesis, Brussels.

Bhat, S.G., Krishnaswami, S., Lal, D., Rama and Moore, W.S., $1969 .{ }^{234} \mathrm{Th} /{ }^{238} \mathrm{U}$ ratios in the ocean. Earth Planet. Sci. Lett., 5: 483-491. 
Buesseler, K.O., Andrews, J.A., Hartman, M.C., Belastock, R. and Chai, F., 1995. Regional estimates of the export flux of particulate organic carbon derived from thorium-234 during the JGOFS EqPac program. Deep-Sea Res. II, 42: 777-804.

Buesseler, K.O., Bacon, M.P., Cochran, J.K. and Livingston, H.D., 1992a. Carbon and nitrogen export during the JGOFS North Atlantic Bloom Experiment estimated from ${ }^{234} \mathrm{Th}:{ }^{238} \mathrm{U}$ disequilibria. Deep-Sea Res., 39: 1115-1137.

Buesseler, K.O., Ball, L., Andrews, J., Benitez-Nelson, C., Belastock, R., Chai, F. and Chao, Y., 1998. Upper ocean export of particulate organic carbon in the Arabian Sea derived from Thorium-234. Deep-Sea Res. II, 45: 2461-2487.

Buesseler, K.O., Benitez-Nelson, C., Rutgers van der Loeff, M., Andrews, J., Ball, L., Crossin, G. and Charette, M.A., 2001. An intercomparison of small- and large-volume techniques for thorium-234 in seawater. Mar. Chem., 74: 15-28.

Buesseler, K. O., Benitez-Nelson, C. R., Moran, S. B., Burd, A., Charette, M., Cochran, J. K., Coppola, L., Fisher, N. S., Fowler, S. W., Gardner, W. D., Guo, L. D., Gustafsson, Ö., Lamborg, C., Masque, P., Miquel, J. C., Passow, U., Santschi, P. H., Savoye, N., Stewart, G., and Trull, T. (2005) An assessment of particulate organic carbon to thorium-234 ratios in the ocean and their impact on the application of ${ }^{234} \mathrm{Th}$ as a POC flux proxy. Mar. Chem., this issue.

Buesseler K. O., Cochran J. K., Bacon M. P., Livingston H. D., Casso S. A., Hirschberg D., Hartman M. C., and Fleer A. P., 1992b. Determination of thorium isotopes in seawater by non-destructive and radiochemical procedures. Deep-Sea Res., 39: 1103-1114.

Burnett, W.C., Corbett, D.R., Schultz, M., Horwitz, E.P., Chiarizia, R., Dietz, M., Thakkar, A. and Fern, M., 1997. Preconcentration of actinide elements from soils and large volume water samples using extraction chromatography. J. Radioanal. Nucl. Chem., 226: 121127.

Cai P., Minhan Dai, Dongwei Lv, and Weifang Chen 2005a. How accurate are the ${ }^{234} \mathrm{Th}$ measurmements in seawater based on $\mathrm{MnO}_{2}$-impregnated cartridge technique? Geochemistry, Geophysics, Geosystems submitted.

Cai, P., Minhan Dai, Dongwei Lv, and Weifang Chen, 2005b. An improvement in the smallvolume technique for determining thorium-234 in seawater, Mar. Chem., this issue.

Cazala, C., Reyss, J.L., Decossas, J.L. and Royer, A., 2003. Improvement in the determination of U-238, Th228-234, Ra226-228, Pb-210, and Be-7 by gamma spectrometry on evaporated fresh water samples. Environ. Sci. Technol., 37: 4990-4993.

Charette, M. and Moran, B., 1999. Rates of particle scavenging and particulate organic carbon export estimated using ${ }^{234} \mathrm{Th}$ as a tracer in the subtropical and equatorial Atlantic Ocean. Deep-Sea Res. II, 46: 885-906.

Chen, J.H., Edwards, L.R. and Wasserburg, G.J., 1986. ${ }^{238} \mathrm{U},{ }^{234} \mathrm{U}$ and ${ }^{232}$ Th in seawater. Earth Planet. Sci. Lett., 80: 241- 251.

Coale, K.H. and Bruland, K.W., 1985. ${ }^{234} \mathrm{Th}:{ }^{238} \mathrm{U}$ disequilibria within the California current. Limnol. Oceanogr., 30: 22- 33.

Coale K. H. and Bruland, K. W., 1987. Oceanic stratified euphotic zone as elucidated by ${ }^{234} \mathrm{Th}^{238} \mathrm{U}$ disequilibria. Limnol. Oceanogr. 32, 189-200.

Cochran, J.K., Barnes, C., Achman, D. and Hirschberg, D.J., 1995a. Thorium-234/Uranium238 disequilibrium as an indicator of scavenging rates and particulate organic carbon fluxes in the Northeast Water Polynya, Greenland. J. Geophys. Res., 100(C3): 43994410.

Cochran, J.K., Hirschberg, D.J., Livingston, H.D., Buesseler, K.O. and Key, R.M., 1995 b. Natural and anthropogenic radionuclide distributions in the Nansen Basin, Arctic Ocean: Scavenging rates and circulation time scales. Deep-Sea Res. II, 42: 1495-1517. 
Cochran, J.K., Livingston, H.D., Hirschberg, D.J. and Surprenant, L.D., 1987. Natural and anthropogenic radionuclide distributions in the northwest Atlantic Ocean. Earth Planet. Sci. Lett., 84: 135-152.

Cochran, J.K. and Masqué, P., 2003. Short-lived U/Th Series Radionuclides in the Ocean: Tracers for Scavenging Rates, Export Fluxes and Particle Dynamics. In: B. Bourdon, G.M. Henderson, C.C. Lundstrom and S.P. Turner (Editors), Uranium-series Geochemistry. Reviews in mineralogy and geochemistry Vol 52. Geochemical Society / Mineralogical Society of America, pp. 461-492.

Colley, S. and Thomson, J., 1994. Particulate/solution analysis of ${ }^{226} \mathrm{Ra},{ }^{230} \mathrm{Th}$, and ${ }^{210} \mathrm{~Pb}$ in seawater by in situ large volume filtration and sorption by manganese oxyhydroxide. Sci. Total Environ., 155: 273-283.

Coppola, L., Roy-Barman, M., Mulsow, S., Povinec, P. and Jeandel, C., 2005. Low particulate organic carbon export in the frontal zone of the Southern Ocean (Indian sector) revealed by ${ }^{234} \mathrm{Th}$. Deep-Sea Res. I, 52: 51-68.

Coppola, L., Roy-Barman, M., Wassmann, P., Mulsow, S. and Jeandel, C., 2002. Calibration of sediment traps and particulate organic carbon using ${ }^{234} \mathrm{Th}$ in the Barents Sea. Mar. Chem., 80: 11-26.

Delanghe, D., Bard, E. and Hamelin, B., 2002. New TIMS constraints on the uranium-238 and uranium-234 in seawaters from the main ocean basins and the Mediterranean Sea. Mar. Chem., 80: 79-93.

Dominik, J., Schuler, C. and Santschi, P.H., 1989. Residence times of ${ }^{234}$ Th and ${ }^{7}$ Be in Lake Geneva. Earth Planet. Sci. Lett.,, 93: 345-358.

Dunk, R.M., Mills, R.A. and Jenkins, W.J., 2002. A reevaluation of the oceanic uranium budget for the Holocene. Chem. Geol., 190: 45-67.

Eppley, R.W., 1989. New production: history, methods and problems. In: W.H. Berger, V. Smetacek and G. Wefer (Editors), Dahlem Workshop on "Productivity of the Ocean: Present and Past". Wiley, New York, pp. 85-97.

EURACHEM/CITAC-Guide, 1995. Quantifying uncertainty in analytical measurements. S.L.R. Ellison, M. Rösslein and A. Williams (eds.), EURACHEM, Berlin.

Feng, H., Cochran, J.K. and Hirschberg, D.J., 1999. ${ }^{234} \mathrm{Th}$ and ${ }^{7} \mathrm{Be}$ as tracers for the transport and dynamics of suspended particles in a partially mixed estuary. Geochim. Cosmochim. Acta, 63: 2487-2505.

Foster, J.M. and Shimmield, G.B., 2002. Th-234 as a tracer of particle flux and POC export in the northern North Sea during a coccolithophore bloom. Deep-Sea Res. II, 49: 29652977.

Friedlander, G., Kennedy, J.W., Macias, E.S. and Miller, J.M., 1981. Nuclear and Radiochemistry. John Wiley \& Sons, New York, 704 pp.

Guo, L., Hung, C.C., Santschi, P.H. and Walsh, I.D., 2002. ${ }^{234}$ Th scavenging and its relationship to acid polysaccharide abundance in the Gulf of Mexico. Mar. Chem., 78: 103-119.

Guo, L., Santschi, P.H., Baskaran, M. and Zindler, A., 1995. Distribution of dissolved and particulate ${ }^{230} \mathrm{Th}$ and ${ }^{232} \mathrm{Th}$ in seawater from the Gulf of Mexico and off Cape Hattera as measured by SIMS. Earth Planet. Sci. Lett., 133: 117-128.

Gustafsson, Ö., Buesseler, K.O., Geyer, W.R., Moran, S.B. and Gschwend, P.M., 1998. An assessment of the relative importance of horizontal and vertical transport of particlereactive chemicals in the coastal ocean. Continent. Shelf Res., 18: 805-829.

Gustafsson, Ö., Düker, A., Larsson, J., Andersson, P. and Ingri, J., 2000a. Functional separation of colloids and gravitoids in surface waters based on differential settling velocity: Coupled cross-flow filtration - split flow-thin cell fractionation (CFFSPLITT). Limnol. Oceanogr., 45: 1731-1742. 
Gustafsson, Ö., Gschwend, P.M. and Buesseler, K.O., 1997. Using ${ }^{234}$ Th disequilibria to estimate the vertical removal rates of polycyclic aromatic hydrocarbons from the surface ocean. Mar. Chem., 57: 11-23.

Gustafsson, Ö., Widerlund, A., Andersson, P. S., Ingri, J., Roos, P., and Ledin, A., 2000b. Colloid dynamics and transport of major elements through a boreal river-brackish bay mixing zone. Mar. Chem., 71: 1-21.

Gustafsson, Ö., Larsson, J., Andersson, P. and Ingri, J., 2005. The POC/234 Th ratio of settling particles isolated using split flow-thin cell fractionation (SPLITT). Mar. Chem., this issue.

Hartman, M.C. and Buesseler, K.O., 1994. Adsorbers for in-situ collection and at-sea gamma analysis of dissolved Thorium-234 in seawater. WHOI, Woods Hole, Technical report WHOI-94-15 pp.

Hussain, N. and Krishnaswami, S. 1980. U-238 series radioactive disequilibrium in groundwaters: Implications to the origin of excess U-234 and fate of reactive pollutants. Geochim. Cosmochim. Acta 44, 1287-1291.

Kersten, M., Thomsen, S., Priebsch, W. and Garbe-Schönberg, C.-D., 1998. Scavenging and particle residence times determined from ${ }^{234} \mathrm{Th} /{ }^{238} \mathrm{U}$ disequilibria in the coastal waters of Mecklenburg Bay. Appl. Geochem., 13: 339-347.

Krishnaswami, S., Graustein, W.C., Turekian, K.K., and Dowd, J.F. 1982. Radium, thorium and radioactive lead isotopes in groundwaters: application to the in situ determination of adsorption-desorption rate constants and retardation factors. Water Resour. Res. 18, 1633-1675.

Ku, T.-L., Knauss, K.G. and Mathieu, G.G., 1977. Uranium in the open ocean: concentration and isotopic composition. Deep-Sea Res., 24: 1005-1017.

Lampitt, R.S., Wishner, K.F., Turley, C.M. and Angel, M.V., 1993. Marine Snow Studies in the Northeast Atlantic: distribution, composition and role as a food source for migrating plankton. Mar. Biol., 116: 689-702.

Liu Z., Stewart G., Kirk Cochran J., Lee C., Armstrong R. A., Hirschberg D. J., Gasser B., and Miquel J.-C., 2005. Why do POC concentrations measured using Niskin bottle collections sometimes differ from those using in-situ pumps? Deep-Sea Res. I, 52: 1324-1344.

Livingston, H.D. and Cochran, J.K., 1987. Determination of transuranic and thorium isotopes in ocean water: In solution and in filterable particles. J. Radioanal. Nucl. Chem., 115: 299-308.

Löfvendahl, R., 1987. Dissolved uranium in the Baltic Sea. Mar. Chem., 21: 213-227.

Mann, D.R., Surprenant, L.D. and Casso, S.A., 1984. In situ chemisorption of transuranics from seawater. Nucl. Instrum. Meth. Phys. Res., 223: 235-238.

McKee, B.A., DeMaster, D.J. and Nittrouer, C.A., 1987. Uranium geochemistry on the Amazon shelf: Evidence for uranium release from bottom sediments. Geochim. Cosmochim. Acta, 51: 2779- 2786.

Moore, W.S., 1990. Sampling and Analytical requirements for a Global Study. In: M.P. Bacon and R.F. Anderson (Editors), Isotopic tracers in U.S. JGOFS. WHOI, Woods Hole, pp. 106-109.

Moran, S.B., Charette, M.A., Pike, S.M. and Wicklund, C.A., 1999. Differences in seawater particulate organic carbon concentration in samples collected using small- and largevolume methods: the importance of DOC adsorption to the filter blank. Mar. Chem., 67: 33-42.

Moran, S.B., Ellis, K.M. and Smith, J.N., 1997a. ${ }^{234} \mathrm{Th} /{ }^{238} \mathrm{U}$ disequilibrium in the Central Arctic Ocean. Radioprotection - Colloques, 32(C2): 169-175. 
Moran, S.B., Ellis, K.M. and Smith, J.N., 1997b. ${ }^{234} \mathrm{Th} /{ }^{238} \mathrm{U}$ disequilibrium in the central Arctic Ocean: implications for particulate organic carbon export. Deep-Sea Res. II, 44: 1593-1606.

Morris, H.W., Livens, F.R., Nolan, L. and Hilton, J., 1994. Determination of Th-234 U-238 Disequilibrium in Fresh-Water Systems. Analyst, 119: 2403-2406.

Nelson, D.M. and D.N. Metta, 1981. Rate of removal of natural thorium isotopes from Lake Michigan water, Argonne National Laboratory.

Nour, S., Burnett, W.C. and Horwitz, E.P., 2002. ${ }^{234}$ Th analysis of marine sediments via extraction chromatography and liquid scintillation counting. Appl. Radiat. Isot., 57: 235-241.

Nozaki, Y., Horibe, Y. and Tsubota, H., 1981. The water column distributions of thorium isotopes in the western North Pacific. Earth Planet. Sci. Lett., 54: 203-216.

Palmer, M.R. and Edmond, J.M., 1993. Uranium in River Water. Geochim. Cosmochim. Acta, 57: 4947-4955.

Pates, J.M., Cook, G.T., MacKenzie, A.B., Anderson, R. and Bury, S.J., 1996. Determination of ${ }^{234} \mathrm{Th}$ in marine samples by liquid scintillation spectrometry. Anal. Chem., 68: 3783-3788.

Pike, S.M., Buesseler, K.O., Andrews, J. and Savoye, N., 2005. Quantification of Th-234 recovery in small volume seawater samples by inductively coupled plasma-mass spectrometry. J. Radioanal. Nucl. Chem.,, 263: 355-360.

Rengarajan, R., Sarin, M.M. and Krishnaswami, S., 2003. Uranium in the Arabian Sea: role of denitirfication in controlling its distribution. Oceanologica Acta, 26: 687-693.

Roberts, K.A. and Santschi, P.H., 2004. Inverse dependency of particle residence times in ponds to the concentration of phosphate, the limiting nutrient. J. Environ. Radioact., 76: 311-318.

Robinson, L.F., Belshaw, N.S. and Henderson, G.M., 2004. U and Th concentrations and isotope ratios in modern carbonates and waters from the Bahamas. Geochim. Cosmochim. Acta, 68: 1777-1789.

Rodriguez y Baena, A.M., Miquel, J.C., Masqué, P., Povinec, P.P. and La Rosa, J., 2005. Single vs. double spike approach coupled with alpha-spectrometry to improve accuracy of ${ }^{234} \mathrm{Th}$ measurements in small-volume seawater samples. Mar. Chem., this issue.

Rutgers van der Loeff, M.M. and Berger, G.W., 1993. Scavenging of ${ }^{230}$ Th and ${ }^{231} \mathrm{~Pa}$ near the Antarctic Polar Front in the South Atlantic. Deep-Sea Res.I, 40: 339-357.

Rutgers van der Loeff, M.M., Meyer, R., Rudels, B. and Rachor, E., 2002. Resuspension and particle transport in the benthic nepheloid layer in and near Fram Strait in relation to faunal abundances and ${ }^{234}$ Th depletion. Deep-Sea Res. I, 49: 1941-1958.

Rutgers van der Loeff, M.M. and Moore, W.S., 1999. Determination of natural radioactive tracers. Chapter 13. In: K. Grasshoff, M. Ehrhardt and K. Kremling (Editors), Methods of Seawater Analysis, third Edition. Verlag Chemie, Weinheim, pp. 365-397.

Rutgers van der Loeff, M.M., Vöge, I. and Lilienthal, H., 2004. Automatisierung einer Fällungs- und Filtrationsprozedur für Wasserproben, Patent applied for, Germany.

Santschi, P. H., Murray, J. W., Baskaran, M., Benitez-Nelson, C. R., Guo, L. D., Hung, C.-C., Lamborg, C., Moran, S. B., Passow, U., and Roy-Barman, M., 2005. Thorium speciation in seawater. Mar. Chem. this issue.

Sarin, M.M., Rengarajan, R. and Ramaswamy, V., 1996. ${ }^{234}$ Th scavenging and particle export fluxes from the upper 100m of the Arabian Sea. Current Science, 71: 888-893.

Sarin, M.M., Bhushan, R., Rengarajan, R. and Yadav, D.N., 1992. The simultaneous determination of ${ }^{238} \mathrm{U}$ series nuclides in seawater: results from the Arabian Sea and Bay of Bengal. Indian J. Mar. Sci., 21: 121-127. 
Sarin, M.M., Krishnaswami, S., Ramesh, R. and Somayajulu, B.L.K., 1994. ${ }^{238}$ U decay series nuclides in the northeastern Arabian Sea: scavenging rates and cycling processes. Cont. Shelf Res., 14: 251-265.

Savoye, N., Benitez-Nelson, C., Burd, A. B., Cochran, J. K., Charette, M., Buesseler, K. O., Jackson, G. A., Roy-Barman, M., Schmidt, S., and Elskens, M. (2005) ${ }^{234}$ Th sorption and export models in the water column: a review. Mar. Chem. this issue.

Savoye, N., Buesseler, K.O., Cardinal, D. and Dehairs, F., 2004. ${ }^{234}$ Th deficit and excess in the Southern Ocean during spring 2001: Particle export and remineralization. Geophys. Res. Lett., 31(12, L12301), doi:10.1029/2004GL019744.

Schmidt, S. and Reyss, J.-L., 1991. Uranium concentrations of Mediterranean seawaters with high salinities. C. R. Acad. Sci. Paris, 312: 379 - 384.

Schmidt, S. and Reyss, J.-L., 2000. Improvement in radiochemical and $\gamma$-counting procedures for the determination of ${ }^{234} \mathrm{Th}$ in seawater. Radiochimica Acta, 88: 459-463.

Schüßler, U. and Kremling, K., 1993. A pumping system for underway sampling of dissolved and particulate trace elements in near-surface waters. Deep-Sea Res. I, 40: 257-266.

Sill, C.W. and Olson, D.G., 1970. Sources and prevention of recoil contamination of solidstate alpha detectors. Anal. Chem., 42: 1596-1607.

Smith, K.J., Vintro, L.L., Mitchell, P.I., De Bois, P.B. and Boust, D., 2004. Uranium-thorium disequilibrium in north-east Atlantic waters. J. Environ. Radioact., 74: 199-210.

Swarzenski, P.W., Porcelli, D., Andersson, P.S. and Smoak, J.M., 2003. The behaviour of Uand Th-series nuclides in the estuarine environment. In: B. Bourdon, G.M. Henderson, C.C. Lundstrom and S.P. Turner (Editors), Uranium-series geochemistry. Reviews in mineralogy and geochemistry Vol 52. Geochemical Society / Mineralogical Society of America, pp. 577-606.

Todd, J.F., Elsinger, R.J. and Moore, W.S., 1988. The distributions of uranium, radium and thorium isotopes in two anoxic fjords: Framvaren Fjord (Norway) and Saanich Inlet (British Columbia). Mar.Chem., 23: 393-415.

Tonkin, J.W., Balistrieri, L.S. and Murray, J.W., 2004. Modeling sorption of divalent metal cations on hydrous manganese oxide using the diffuse double layer model. Appl. Geochem., 19: 29-53.

Trimble, S.M. and Baskaran, M., 2005. The role of suspended particulate matter in ${ }^{234} \mathrm{Th}$ scavenging and ${ }^{234} \mathrm{Th}$-derived export fluxes of POC in the Canada Basin of the Arctic Ocean. Mar. Chem. 96, 1-19.

Trull, T.W. and Armand, L., 2001. Insights into Southern Ocean carbon export from the $\delta^{13} \mathrm{C}$ of particles and dissolved inorganic carbon during the SOIREE iron release experiment. Deep-Sea Res. II, 48: 2655-2680.

Turnewitsch, R. and Springer, B.M., 2001. Do bottom mixed layers influence ${ }^{234}$ Th dynamics in the abyssal near-bottom water column? Deep-Sea Res. I, 48: 1279-1307.

Usbeck, R., Rutgers van der Loeff, M.M., Hoppema, M. and Schlitzer, R., 2002. Shallow mineralization in the Weddell Gyre. Geochemistry, Geophysics, Geosystems, 3: $2001 \mathrm{GC} 000182$.

Vogler, S., Jung, M. and Mangini, A., 1996. Scavenging of Th-234 and Be-7 in Lake Constance. Limnol. Oceanogr., 41: 1384-1393.

Waples, J.T., Orlandini, K.A., Edgington, D.N. and Klump, J.V., 2004. Seasonal and spatial dynamics of Th-234/U-238 disequilibria in southern Lake Michigan. J. Geophys. Res., 109, C10S06, doi:10.1029/2003JC002204.

Waples, J.T., Orlandini, K.A., Weckerly, K.M., Edgington, D.N. and Val Klump, J., 2003. Measuring low concentrations of ${ }^{234} \mathrm{Th}$ in water and sediment. Mar. Chem., 80: 265281. 
Waples, J.T., Benitez-Nelson, C., Savoye, N., Rutgers van der Loeff, M., Baskaran, M. and Gustafsson, Ö., 2005. An Introduction to the Application and Future Use of ${ }^{234} \mathrm{Th}$ in Aquatic Systems. Mar. Chem., this issue.

Windom, H., Smith, R., Niencheski, F. and Alexander, C., 2000. Uranium in rivers and estuaries of globally diverse, smaller watersheds. Mar. Chem., 68: 307-321.

Zar, J.H., 1996. Biostatistical Analysis. Prentice Hall International, Upper Saddle River, New Jersey. 